\title{
L'aportació lèxica de Josep Bernat i Baldoví, dins del context literari dels segles XVIII i XIX
}

\author{
JoAquim MarTí MeSTRE \\ (Universitat de València. \\ Institut Interuniversitari de Filologia Valenciana) \\ joaquin.marti@uv.es \\ Recibido: mayo de 2012 Aceptado: junio de 2012
}

\begin{abstract}
Resum: Amb l'estudi comparatiu i evolutiu d'alguns mots d'interés lexicogràfic: fleca, guit, barret / barretina / capell / muntera / sombrero, torcaboca / tovalló, comare / madrina / matrona / comadrona, bou / toro i palleta / lluquet, juntament amb altres veus, es demostra la importància dels escriptors de vocació popular, com Josep Bernat i Baldoví, en el coneixement del lèxic històric català, en un període tradicionalment poc aprofitat. Així mateix, l'estudi evolutiu del vocabulari ajuda a copsar els canvis en els costums i en les mentalitats.
\end{abstract}

Palabras clave: Història del lèxic català. Segles XVIII i XIX.

Resumen: Con el estudio comparativo y evolutivo de algunas palabras de interés lexicográfico: fleca, guit, barret / barretina / capell / muntera / sombrero, torcaboca / tovalló, comare / madrina / matrona / comadrona, bou / toro i palleta / lluquet, junto a otras voces, se demuestra la importancia de los escritores de vocación popular, como Josep Bernat i Baldoví, para el conocimiento del léxico histórico catalán, en un período tradicionalmente poco aprovechado por los lexicógrafos. Por otra parte, el estudio evolutivo del vocabulario ayuda a percibir los cambios en las costumbres y las mentalidades.

Mots clau: Historia del léxico catalán. Siglos XVIII y XIX.

Escriptors «populistes» com Josep Bernat i Baldoví (Sueca 1809 - València 1864) han arrossegat durant molts anys un prejudici injust, que ha resultat molt negatiu per al seu coneixement i estudi. Teodor Llorente, en una coneguda carta adreçada a Joaquim Rubió i Ors, del 22 de desembre de 1877, situava l'inici de la Renaixença valenciana l'any 1859, amb Vicent W. Querol i amb ell mateix -amb el precedent de Tomàs Villarroya el 1841-, mentre que incloïa Josep Maria Bonilla i Josep Bernat i Baldoví dins de la «literatura po- 
liticopopular», entre els escriptors que «no se preocupaban para nada del renacimiento de las letras lemosinas», tot establint «una diferencia completa, una separación absoluta entre los que cultivamos la poesía lemosina docta y los que escriben en valenciano vulgar para el teatro o para los periódicos callejeros» (cf. Simbor 1980: 14-17). Per tant, així, al mateix temps que reivindicava la poesia com l'únic gènere conreat per la Renaixença valenciana, desqualificava altres manifestacions literàries com el teatre i la premsa, que en aquesta època era en gran part un exercici de creació.

L'opinió de Llorente va pesar molt, però afortunadament, en els darrers anys, aquest enfocament reduccionista ha canviat, i hom comença a valorar convenientment l'obra d'autors anteriors a Teodor Llorente, practicants d'una estètica diferent a la del patriarca de la Renaixença, com Joan Baptista Escorigüela, Josep Maria Bonilla o Pasqual Pérez, o d'altres del segle XVIII com Carles Ros o Carles Leon. Així mateix, es revaloren les manifestacions «populars», com la premsa satírica o el teatre de costums. Ja va dir Vicent Simbor (1980) que en la «peça valenciana» «teníem les bases ben fetes per a assolir un teatre de pretensions en la llengua del país», i si això no es va assolir en un futur no va ser per culpa de Bernat i Baldoví, el qual, de fet, va sentar les bases del teatre costumista valencià.

Per entendre l'autèntica significació de l'obra de Bernat, evitant desqualificacions apriorístiques, cal situar-la dins del context cultural del seu temps i dins de la tradició literària de la qual forma part. En Bernat i Baldoví convergeixen diverses influències literàries, procedents de la cultura còmica popular, del costumisme i de l'hedonisme. Hi trobem especialment l'empremta dels col-loquis valencians dels segles XVII, XVIII i XIX (amb autors com Carles Ros, Carles Leon, Joan Baptista Escorigüela o Manuel Civera), també de la comèdia burlesca, a través sobretot de La infanta Tellina i el rei Matarot atribuïda al pare Mulet, i de la prosa burlesca i costumista, a través d'obres com la Rondalla de rondalles de Lluís Galiana. Així mateix, manté semblances temàtiques i ambientals amb la poesia festiva, satírica i eròtica dels segles XVII i XVIII. Amb aquestes coordenades estètiques, l'obra de Bernat i Baldoví se situa dins d'un corrent de literatura costumista, satírica i festiva, de tradició autòctona, i que als segles XVIII i XIX triomfava també en les lletres castellanes (sainets, comèdies burlesques, literatura de canya i cordell, prosa costumista $\mathrm{i}$ periodística) i internacionalment a altres països europeus, com França o Anglaterra. ${ }^{1}$

Teodor Llorente acusava els escriptors com Bonilla i Bernat i Baldoví de prendre el valencià «como lo habla el pueblo, para dejarse comprender de él». Però açò, de fet, des d'un punt de vista lingüístic, o historicolingüístic, ho podem entendre no com un defecte, sinó com una virtut. Sabem que la recerca del verisme fou un aspecte clau dins del costumisme, i aquesta recerca té lloc

${ }^{1}$ Per als elements literaris de tradició popular i burlesca en Bernat i Baldoví, veg. Martí (2009). 
en gran part a través del llenguatge, particularment del lèxic. Per això Josep Bernat es va esforçar per reproduir en els seus escrits el valencià col-loquial i popular del seu temps, el «llenguatge de la plaça pública», que deia Bakhtin (1999 [1941]), amb la qual cosa la seua obra és una font ben valuosa per conéixer la llengua parlada del passat, i en aquest sentit, hi ocupa un lloc destacat el lèxic. Colón (2002: 328, 330) ja va assenyalar que Bernat i Baldoví «es trobava en un món rural, encara no massa influït per la civilització tècnica», $i$, per això «el seu llenguatge té una immediatesa extraordinària» $i$ «és una mina en l'ús d'un lèxic valencià ben autèntic, no gens influït per modes forasteres». Es tracta d'un model lingüístic i lèxic que té els seus antecedents immediats en els col-loquis valencians dels segles XVII, XVIII i primera meitat del XIX, el qual va fer seu el nostre autor, adaptant-lo a les característiques de la seua obra, més complexa i variada que la dels col-loquiers, i que, a través d'ell, va poder passar al teatre valencià de vocació popular que va florir especialment a la segona meitat del s. XIX i les primeres dècades del XX. En aquest sentit, Josep Bernat és una figura clau en la transmissió i l'evolució literària de la varietat lingüística popular i del registre col-loquial valencià moderns.

Són prou nombroses les veus utilitzades per Bernat i Baldoví que aporten novetats respecte als nostres principals diccionaris històrics i etimològics (DCVB i DECat), des de mots, locucions o accepcions no registrades o no documentades, fins a primeres documentacions o a la presència en Bernat, i per tant en valencià, de formes que aquests diccionaris excloïen del nostre dialecte. És el cas, per exemple de fleca 'forn de pa i botiga on venen el pa': «De Silla pasí a Sollana, / a hon, asaltant una fleca, / trenquí el orgue a lleña seca» (A 12). Coromines (DECat, IV, 31-32) no troba documentació clara de fleca designant l'establiment on es ven o es pasta el pa fins l'any 1518, en l'Spill de Castellbò, i considera que amb aquest sentit «no hi ha proves que s'hagi dit mai a fora del Principat (...); més aviat sembla que hagi estat estrany de sempre (...) al rossellonés, a les Illes i al País Valencià»; més antiguitat troba a la combinació pa de fleca, datada des del s. XIV, per referència al «pa de venda», diferenciat del «pa de casa». ${ }^{2} \mathrm{El} D C V B$, que aporta documentació només de pa de fleca, informa que, a Mallorca, «no fa gaire anys que els vells encara deien pa de fleca al pa blanc», i recull a València l'expressió «Eixe xiquet és un fartó; es menjaria una fleca sencera!», així com una cançó infantil procedent de Cullera, on apareix el diminutiu flequeta: «Este és el pare; / esta la mare; / este demana pa: / este diu que no n'hi ha; / este diu: «gorrinxet, gorrinxet, / a la flequeta estarà»». El testimoni de Bernat no és l'únic que confirma l'ús de fleca referit a l'establiment en terres valencianes. En efecte, el trobem als segles XVI, XVII i principis del XVIII en diversos documents ad-

\footnotetext{
${ }^{2}$ En realitat, el pa de fleca era el pa fet a la fleca, que els clients compraven; el trobem, per exemple, l'any 1648, en l'inventari dels béns de l'herència de Melcior Polo, de Morvedre: «dos caixes de tenir lo pa de fleca, la una gran y altra chiqueta, buides» (Martínez Rondán 1984: 218).
} 
ministratius (ordenances, estatuts, privilegis, establiments, cartes de poblament), arreu del País Valencià; per exemple: «Pere Benavent, flaquer, arrendador de la fleca de dita vila» (Quatretonda, a. 1587) (Benavent 1987: 49), en les Ordinacions de la Jana: «com són preus de arrendaments de forns, fleca, taverna e altres semblants» (a. 1596) (Carbonell 2003: 137), en el llibre del mustassaf d'Algemesí (segles XVI-XVII): «quant se aja de donar [a] cascuna qüerna en pasta per los flaquers que tenen arrendada la fleca y dre[t] de pastar» (Escartí 1992: 105), «Ittem, que puixen arrendar tenda, fleca y taverna» (Albalat de la Ribera, a. 1603) (Hernandis 2007: 191), en els Establiments de Vinaròs (1648): «establim que tots lo flaquers de la present vila estiguen tenguts y obligats a tenir pa per a vendre en ses fleques» (Albiol 2003: 233), o en el «Repertori e índex dels estatuts i ordinacions de Vila-real per abesedari» (a. 1711): «Flequers, si no tenen pa en la fleca, en quina pena cauen» (Gil Vicent 2002: 188).

Els documents antics mostren que els flequers eren diferents dels forners, com també ho eren la fleca i el forn: el Libre del mostassaf de Mallorca, del segle XV, conté uns «Capítols dels flaquers e de les flaqueres» i uns altres capítols «Dels forners» (Pons 1949: 13-19); en el Readreç de los capítols de l'offici de mustaçaf, de les cizes e imposicions (1611) d'Alzira (pp. 198199) hi ha un capítol dels «flaquers» i un altre «De forns y forners»; segons les disposicions de cada capítol, els flaquers pastaven el pa, el coïen en la fleca, i després el venien, mentre que els forners coïen en el seu forn el pa que havien pastat els flaquers o els casolans, és a dir, els clients que pastaven el pa a sa casa i el duien a coure al forn, i també coïen al forn les diverses pastes o menjars que havien fet els casolans: «que tot forner haja de tenir y tinga en son forn un pes y pedres, marcat y adreçat per a pesar lo pa als flaquers», «que ningun forner o amo de forn ni altra persona alguna gose repastar, ço és, que de la farina e pasta sua pròpria o de altri no gosse fer pa per a vendre a modo de pujes», «que ningun forner gose per si ni per altri pesigar los pans dels casolans», «que tots los forners tinguen obligació de coure les casoles, pasticeres y altres coses semblants de sos casolans sens interés» (Lairon 2001: 198-199); igualment, en la carta de poblament del Llocnou d'En Fenollet (1611) es diferencien clarament les funcions públiques del forn i de la fleca: «y que los dits pobladors y sos succesors de dites cases y terres tinguen obligació de coure en lo forn, moldre en lo molí (...), comprar en la tenda, fleca, carniseria y taverna» (Zaforteza 1948: 17) ${ }^{3}$.

També es documenta fleca en textos literaris populars valencians dels segles XVII-XVIII i XIX: en La infanta Tellina: «y en les fleques les fogases / ben fetes y de bon pa» (Llombart, ed., Obres festives ab lo Tractat del pet com-

\footnotetext{
${ }^{3}$ Aquesta mateixa distinció entre el forn i la fleca es troba en altres documents contemporanis, com les cartes de poblament del comtat de Cocentaina (Pla Alberola 1986: 53-54, 86, 116-117) o les del Camp de Morvedre (Iborra Lerma 1981: 390, 398). Vegeu també Simón (1946).
} 
postes, segons antiga, general y molt rahonable tradició, pel pare Francesch Mulet, València, 1876, 184), en Les marors de una fadrina (València, 1860), de Rafael Vives: «Em pareix que este és bon mos; / digo, y en Ibi, la fleca» (p. 30); en un col-loqui de 1735 apareix l'expressió fer fleques: «Grans partides de huit lliures / de forment à fet portar, / y a tretse y micha el venia / als pobrets dels valencians. / Per ell à.gut de fer fleques / nostra mare la ciutat» (a. 1735) (Blasco 1984: 152), ${ }^{4}$ que ja trobem al segle XV en el Mostassaf de Mallorca: «que d'assí avant los forners, qui fan o faran flaca, haien a tenir cascun dia les taules e venadores bastes de pa» (Pons 1949: 17) .

El mot continua en els diccionaris valencians del segle XIX, des d'Escrig, que el recollia amb $e$ oberta i amb $e$ tancada: flèca o fleca 'panadería, por el sitio, casa o lugar donde se hace o vende el pan'; ${ }^{6}$ EscLl es decidia per l'accent greu: flèca 'panadería', mentre que Pla i Costa ho feia per l'agut: fléca 'panadería' (Martines 1998: 163), i MGad tornava a la doble forma: flèca, fleca 'tahona'. V. panaderia. El mot fleca és recollit en l'ALDC (m. 1055 «La fleca») en valencià en alguns punts de la Plana i de la Ribera: A 1'Alcúdia de Carlet, Alberic, Castelló de la Plana i la Llosa, amb [e] ([fl'eka]), i a Albalat de la Ribera amb [ ] ([fl' ka]). Aquesta dualitat de timbre, deu explicar, doncs, la doble accentuació de la qual es feien ressò els diccionaris valencians vuitcentistes. ${ }^{7}$ Tant a Castelló com a la Llosa fleca consta a l'ALDC com a primera resposta, per davant de forn 'lloc on couen el pa' (Castelló), i de panaderia (la Llosa); a l'Alcúdia la fleca és la «cantitat de pa que se fea en el forn, per a distinguir-lo del que cada dona fea a casa», igualment, a Alberic, la fleca és la «cantitat de pa que abans es fea en el forn per a vendre», diferenciant-lo del pa que «cada u es fea (...) a casa seua», i a Albalat de la Ribera el pa de fleca és el 'pa que feien al forn i que era més dolent que el pa de casa'. Germà Colón (1997: 425) confirma la continuïtat de fleca a la capital de la Plana: «quantes vegades no hauré anat a ca la fleca, o hauré menjat rollets de fleca!» Beltran (2010: 402) diu que fleca és poc usat al Maestrat, però a Castelló és «usat per tot arreu. Diuen la fleca a totes les panaderies de pa corrent i fi». Fausto (2006: 46) recull a Vila-real fleca 'forn de pa', 'botiga on es ven pa', com un mot «en perill d'extinció»; i, ja en terres aragoneses, el mot fleca 'tahona' es registra també en el català de Fraga (Galán, 1997: 28).

\footnotetext{
${ }^{4}$ A diferència de Blasco, que modernitza el text, fem la transcripció mantenint la forma del ms.

${ }_{5}$ Aquesta expressió recorda pastar a fleca, que Coromines (DECat, IV, 32) cita en un document d'arxiu del segle XV o finals del XIV, i sobre la qual diu que «no és un testimoni clar ni segur de fleca com a establiment, car en rigor es pot entendre com una forma abreujada de dir «pastar (a la manera) del pa de fleca»».

${ }^{6}$ Escrig distingeix gràficament les $e e$ i $o o$ obertes de les tancades mitjançant «un acento grave,

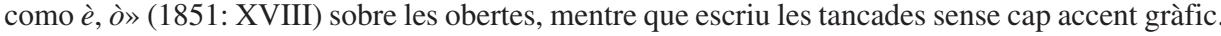
${ }^{7}$ Coromines creia que Escrig copiava el mot fleca de fonts del Principat, basant-se, precisament, en la dualitat accentual del lexicògraf valencià. Ara veiem que segurament el doblet flèca o fleca d'Escrig responia a una realitat fonètica valenciana.
} 
Així mateix, a Sueca les persones grans recorden encara fleca referit a l'establiment on es venia el pa i la farina, i la variant freca, ${ }^{8}$ que designava la post on es posava el pa pastat a casa que duien a coure al forn, tapat amb una tela blava. ${ }^{9}$ El mot fleca, referit al forn on es venia el pa, forma part també de la paremiologia valenciana, segons el recull Alberola (1928: 246): Qui va a la fleca y a la taberna família agena governa. ${ }^{10}$

La vigoria que aquest tipus lèxic ha tingut en terres valencianes és confirmada pels derivats flequejar (i flaquejar), referit a l'acció de fer pa, no enregistrat en el $D C V B$ ni en el DECat: ${ }^{11}$ «tot moledor de farina de forment a obs de flequegar, pach d'imposició per cascun caffiç (...) dos sous» (Xàtiva, a. 1378) (Mira, Guinot 2008: 145), ${ }^{12}$ «per rahó de una letra que lo dit governador havia manada a requesta de Pere Compte contra lo mustaçaf..., manant al dit mustaçaf que.1 lexàs flaquegar» (Vila-real, a. 1423-24) (Doñate 1979: 447), «que tot flaquer o flaquera que moldran forment per obs de flequejar o de vendre aquell en pasta o cuit o pa fet, pague per cascun cafís deu sous de siza» (a. 1611) (Lairon 2001: 217), i flequeria (flaqueria) 'ofici de flequer': "Encara ordenaren que, si serà atrobat que alguna flaquera compre blat ab frau, que sia gitada del offici de la flaqueria per tot l'any» (a. 1311) (CICA: 2006 - Manual I, p. 85, 1. 26), i com a sinònim de fleca: «que la flaqueria... de ací anant no se arrende, sinó que sia donada franquament, emperò que y haja de haver contínuament dos flaqueries, segons se practicava» (Vila-real, a. 1508-09) (Doñate 1979: 447), «que dits vasalls sien obligats a totes les ragalies del senyor, ço és, (...) coure en los forns del senyor, comprar en les tendes del senyor, y pa en la flaqueria del senyor» (Carlet, a. 1610) (Benítez 1986: 209). Bernat també fa servir el substantiu fleguer: «Sinse pena y sinse goch, / hi à así un fleguer brut de fanc / que sisaba en lo pa blanc» ( $S$ 151), interessant variant de flequer amb -g-, si no és una errada, no registrada en el $D C V B$ ni el $D E C a t$; en els textos valencians antics, generalment flequer o, més sovint, flaquer.

Quant a l'etimologia, Coromines (DECat, IV, 29-36) considera inversemblant la proposta de Montoliu de partir d'un verb flacar (< llatí *FLACCARE 'amollir, ablanir'), i creu que el català fleca seria d'origen germànic, amb l'arrel flec-, i no

\footnotetext{
8 Variant explicable per un canvi de líquides, semblant al que trobem en altres mots com frassada (i frassà) 'flassada' (DCVB a la Ribagorça i l'Alguer, ALPI núm. 706c a Moixent), en la mateixa posició sil-làbica, i en altres posicions: arcaduf, sarpasset, tarús 'talús' (cf. Martines, 2000: 183). ${ }^{9}$ La tradició de portar així el pa al forn és ben antiga. En l'inventari dels béns mobles de l'Hospital General de València de 1584-85 llegim: «Item, sis tovalloles per a les postetes que porten lo pa al forn, de les quals les sis són de llens nou» (López Terrada 1986: III, 1014).

${ }^{10}$ El refrany va acompanyat de la glossa panaderia, per relació a fleca.

${ }^{11}$ En el $D C V B$ es documenta al segle XIV un verb flecar 'fer pa', que Coromines (DECat, IV, 32$33) \mathrm{creu}$ «mancat de tot fonament».

${ }^{12}$ Com diuen Mira i Guinot (2008), en el cas de Xàtiva, l'impost de la moltura per l'ús del molí afectava tots els veïns, «a obs de flequegar»; per tant, entenem que el verb flequejar 'fer pa' s'aplicava no sols al sector professional (flequers), sinó també als particulars que pastaven per al consum propi.
} 
pas flac-, i explica la variant amb $a$ en la primera sílllaba flaquer com una dissimilació normal en el context $e$...é $>a$ a..ée. Siga com siga, cal tenir en compte que en els documents valencians antics les formes amb $a$ inicial en flaquer $\mathrm{i}$ altres derivats són molt nombroses, molt més que les corresponents amb $e .^{13}$

L'adjectiu guit '(animal) que acostuma a tirar guitzes' el $D C V B$ el registra només al Principat, i Coromines (DECat, IV, 747), que el documenta en un text de c. 1520, aplicat a una mula, afirma haver-lo sentit «a tot el Principat des de les més altes valls pirinenques (Cardós, Boí, Aran) fins a Vinaròs»; però, com veiem, també es coneixia més al sud: «y en un bell en sec peguen una esquivà cap a arrere, a estil de mula guita» $\left(D\right.$ 52). ${ }^{14}$ Coromines no el recull «en lèxics anteriors a Belv. i Labèrnia», però ja el va arreplegar Carles Ros (1764): guit, a 'se aplica al mulo, mula u otro animal de carga que es falso u indómito', i continua en els diccionaris valencians del XIX: en Escrig guit o guito 'falso, sa. Se aplica al caballo, mula u otra bestia que tiene resabios que no se conocen, y que aun sin tocarla tira coces', juntament amb el sinònims guitó i guitoner; i igualment en EscLl i MGad. Forma locucions, eixir la mula guita (a algú): «-Ven aquí y no seas nesia. / -Ca! Li ha exit la mula guita. / -Mergalita!... Mergalita!... / -Mergalita pren iglésia» (Escalante, II, 564), l'agüelo Cuc vol seduir Mergalita, però ella no s'hi deixa; comparacions: ser (algú) com la mula guita: «ella és com la mula guita, / y, aixina fen-se la tonta, / si eres bobo y et descuides / (...), t'aventa un parell de coses / que te rebenta o t'encoixa» (Palanca i Roca, Secanistes de Bixquert o Al vell carabasa en ell, Xàtiva, 1867, 13), per referència a una xicona de la qual hom no es por fiar, fer més por (algú) que una mula guita: «-Yo no espante a ningú, y manco a tu. -Si me fas més por qu·una mula guita!...» (Morante, L'alcalde de Favara, València, 1947, 26), i refranys: Mula guita, ven-la pronte (Alberola 1928: 174), Lliga-la curta, qu'és guita (id., 160), De l'ase manso tots van prop, y del guit fuig tothom (id., 57). També en aragonés guito 'bestia falsa y coceadora', doc. des de 1652 («mula guita») (DCECH, III, 279-280), i en gascó guit, guite 'cheval ou jument qui mord ou rue', 'bête vicieuse' (Rohlfs, 1977: 66). ${ }^{15}$

${ }^{13}$ Si tenim en compte les dades objectives del CICA, en els documents valencians d'aquest corpus, entre els segles XIV i XVII, es registren 85 casos de flaquer, $a$, i 13 de flaqueria, mentre que tan sols hi ha dos casos de flequera i quatre de flequeres. Ara bé, en altres textos occidentals dels segles XIII i XIV, els Costums de Tortosa (1272) i el Llibre de consells de la Paeria de Cervera (1332-33), només es documenten formes amb e: flequer, a, flequeries.

${ }^{14}$ Cf. guit 'guitza, coça', que Coromines (DECat, IV, 745) considera peculiar del Camp de Tarragona, i guita, amb el mateix sentit, que recull a Santa Coloma de Queralt i al Vallès. També en terres valencianes, guit 'coça' a Castelló, al costat de còs (Colón 2011b: 359), i a Benifairó de les Valls guit 'coça pegada amb una sola pota' (ALDC núm. 95 «La coça»).

${ }^{15}$ Segons Coromines (DECat, IV, 746), guit «des de les [valls] catalanes s'estén a totes les altes valls gascones i aragoneses»; en canvi, Colón (1993: 77-78) situa el cat. guit i l'arag. guito entre les isoglosses compartides per ambdues varietats, la majoria de les quals «reposen en una afinitat lèxica entre tots dos dominis i són molt antigues». 
El DCVB localitza la locució tirar el barret al foc 'irritar-se molt per una contrarietat invencible' al Maresme, a l'Empordà, a Mallorca i a Menorca. ${ }^{16}$ Amb tot, també és coneguda en valencià. La utilitzava Bernat i Baldoví: «-Home, com en La Donsayna del dumenche anterior feres tan mala cara y te'n puchares tant de punt, volia saber només si t'has chelat ya algo. (...) -Veritat és, Sueco, però a voltes no és u dueño de la seua persona y tira el barret al foc per manco de dos dinés» ( $D$ 82), «No em sap mal cullga una llima / Chima, / ni que prenga una magrana / Chuana, / però com me toque res / Inés, / o em pesigue un albercoc / Roc..., / tiraré el barret al foc, / y eu pagaran tots els cuatre» ( $T$ 35). I era prou habitual en els textos valencians populars dels segles XVIII, XIX i primeres dècades del XX. Vegem-ne alguns exemples: «Maria Santísima, quin dia de chuí! Yo de veres li confese que hi à per a tirar el barret al foc (...). Jesús, Jesús!» (El Mole, 1837, I, 260), «-Ya els ha conegut el choc. / No em parle de nucs ni llasos, / que me s'han unflat els nasos, / y tire el barret al foc. / Des de hui no els nesesite, / ni a vosté ni a son nevot. / Yo me hu arreglaré tot. / (...) -Aixina, tire-los fora» (Balader, El pare alcalde, València, 1871, 26), «pert u la calma, y li fan / tirar al foc el barret» (Escalante, II, 389), «No m'ofenga, / o tire el barret al foc» (Ovara, L'ànima en un fil, València, 1881, 10), «És qu estaba pensant en la doña Bragasa eixa, que té la culpa de tot... Pepe, tira el barret al foc y acaba de una vegà...» (Comes, Les pilotes de Nadal, València, 1928, 14). Bernat i Baldoví juga humorísticament sobre aquesta locució, canviant foc per aigua: «Mes chirem así la fulla (...), perquè si em lleve la chupa y tire el barret a l'aigua (que sempre no s'ha de dir al foc), pegaré cuatre esclafits» (D 19), i barret per gorra: «Encara em faran tirar a mi també el barret al foc, o a lo manco la gorra, que (...) tinc molt males cosquerelles» (D 125). En aquest altre text la fam, personificada, que ha fet patir durant molt de temps la població valenciana, vençuda gràcies a la intervenció de sant Vicent Ferrer, tira el barret al foc, és a dir, desisteix i es retira: «Mes predicant Vicent (...), / la predicció tingué son lloch; / puix de forment vingué tant copiós rech, / que ya la fam tirà el barret al foch» (a. 1745) (Furió 2001: 134). També podia significar 'prendre i manifestar una gran alegria, congratular-se', tal com la trobem en Bernat i Baldoví: «tots en honor del soldat / tiren hui el barret al foc» (Mi 135), i en altres textos valencians de l'època: «y en lo dia de la nóvia tots (...) estigueren ben de tayna, perquè tiraren el barret al foch, com aquell que diu, (...) que tot anava al bol» (Pellicer, 1986: 218), «Sols me queda ara contar / una atra gran noticiota, / que, si fóra veritat, / tirava el barret al foc, / y después, per lo pesar, / me bevia quatre miches / de aquell vi del Pla de Quart / que tu sabes, Miguelito / -Molt guapo és, tio Bernat, / però asò no és de l'asunto» (a. 1815) (Branchat, Conversasió que tingueren el tio Bernat... y Miquelo el Tosut..., sobre les notícies que han corregut y corren de Malapart, BUV, ms. 661, 66), on cal entendre el pesar en sen-

\footnotetext{
${ }^{16}$ En Espinal (2006: 448) tirar el barret al foc 'renunciar, irritat, a prosseguir una acció', 'descoratjar-se, deixar córrer alguna empresa, etc., per causa d'una contrarietat'.
} 
tit irònic, ja que la noticiota no és altra que la desitjada mort de Napoleó. Igualment, tirar el barret en alt era mostra d'alegria, com veiem en aquest fragment de la Colecsió de conversacions entre Saro Perrengue i el Dotor Cudol, de Manuel Civera, de l'any 1820 (València, Francisco Brusola, p. 71): «Les campanes voltechant, / tots llevant-se les munteres, / tirant els barrets en alt». Bernat també feia servir la locució tirar el barret al patxo: «quin home és tan macho / que, habent dona que l'empotre, / no tire el barret al pacho, / y la manta allà al refotre?» $(V 24)$, per relació a Visanteta, quan tracta de seduir Pascualo.

El mot barret convivia en el valencià del segle XIX amb el castellanisme sombrero, i tots dos els veiem en el següent text de Bernat i Baldoví, per relació a la locució que ens ocupa: «Posa-los pronte en son lloc, / si no, a falta de barret, / tiraré el sombrero al foc» (B 7). I, així mateix, el Sueco feia servir barret per referència a una peça de vestir amb què els llauradors es cobrien el cap: «Cualo no fa més que pegar-li voltes al barret» (V 23), «Lleva't el barret» $(P 16)$, ordena el fiel al llaurador Pasqualo, quan ha de parlar davant l'alcalde; «Portava (...) un barret de color de tomata, que li servia de funda o de tapaora a un cap de cohombro, més pelat que una carabasa» (D 116), el llaurador Casimiro Sardinola; «Sempre es queden com... Vaoro. És dir, en lo barret al tos, y la punteta del nas a l'aire» (S 168), «La fortuna fon que portaba barret» (S 199), el llaurador Tòfol. En aquest altre fragment ens apareix juntament amb sombrero en la mateixa oració, però aplicat a objectes distints: «Per a no llevar-se el sombrero a ningú del món (...), lo millor de tot és... portar barret» ( $D 46)$.

Segons el DCVB i el DECat (I, 681-683), el barret antigament designava una peça de roba sense ala que s'adaptava al cap per cobrir-lo i abrigar-lo, «una espècie de bonet». ${ }^{17}$ Aquest valor, segons Veny (2009a: II, 73), el manté encara el balear. ${ }^{18}$ Per tant, era un objecte diferent del capell 'peça de vestir que serveix per a cobrir el cap, consistent ordinàriament en un casquet $\mathrm{i}$ una vora $\mathrm{o}$ ala tot al voltant' $(D I E C)$.

El DCVB i Maranges (1991: 59-60) documenten barret per primera vegada en Lo somni de Bernat Metge, on el portava el rei Joan quan se li apareix a l'autor: «ab un barret vermell en lo cap». Coromines (DECat) el recull des de la segona meitat del segle XIV: en Turmeda, en un document de 1388 procedent de Santa Coloma de Queralt (citat pel DAg.): «un barret obrat de seda e de fil d'or», on

\footnotetext{
17 Amb paraules del $D C V B$, 'peça de roba o d'altra matèria que s'adapta al cap per cobrir-lo i no té ventalla'; Coromines (DECat) confirma aquest sentit: «el barret era antigament una peça de roba que cobria el cap i no baixava d'aquest, no pas un capell». També en occità el mot berret (barret) designa un 'couvre-chef de laine, plat et sans bord, des paysans basques, béarnais et gascons' (Mistral 1979: I, 272), 'coiffure en laine plate' (Alibert 2002: 155), i berreto 'bonnet de nuit' (Mistral 1979: I, 272).

18 També el DCVB i el DECat recullen en l'actualitat aquest sentit de barret en balear; Coromines (DECat) afegeix que «a l'Alt Pallars un casquet de capellà s'anomena barret» i que al Rosselló «deu ser antiga l'aplicació a un bonet o a una boina ampla».
} 
veiem que era un objecte ric i luxós, i en el Valeri Màxim d'Antoni Canals, on designa un objecte litúrgic que portava el sacerdot Sulpício. Un anys abans, a la primera meitat del segle XIV, el trobem en les Ordinacions de la casa $i$ cort de Pere el Cerimoniós, on té un ús acadèmic, com a distintiu dels doctors: «per tal com los doctors qui han reebut lo barret en qualsevol sciència han grau de dignitat» (a. 1344) (CICA: 2006 - «Ceremoniós I», p. 193, 1. 1). Maranges (1991: 59) recull, entre altres, un barret que portaven cavallers, un rei d'armes (en el $\mathrm{Ti}$ rant), o un treballador, així com, en un inventari de 1430, un barret amb el qual hom es cobria el cap per dormir; i afegeix que els materials trobats en els barrets «són la llana i el vellut, i els únics colors, el negre i el vermell».

A la segona meitat del segle XV trobem l'ús del barret com a signe de cortesia, entre cavallers que es disposen a lluitar (assenyalar cortesia de barret): «Si per cas los dos qui la batalla hauran a ffer se ancóntran en ajust o per carrera, ¿quina demostració entre ells se deu tenir? Lo requeridor deu al deffenedor primer assenyallar cortesia de paraula o de barret, no molta sinó ab continensa; no soperbiosa, car no sap la fi quina serà» (CICA: 2006 - Turell, «Arbre», p. 102, 1. 23). També al segle XV, veiem el barret, ornat ricament, cobrint el cap d'argenters: «puys vengueren los argenters ab robes folrades de pell de mars, ab collars e cadenes d'argent e molts qui aportaven de richs fermals, uns en los pits, altres en los barrets» (CICA: 2006 - Safont, «Dietari», p. 188, 1. 35), i, d'altra banda, un barret blanch, molt més humil, que portava «un boemià que stave en camisa» (Farreny 2004: 26). Ja al segle XVI, «com vingué a la hora del jurar, lo emperador [Carles V] levà's los guants y lo barret, y posà les mans damunt lo misal» (Martí 1994: I, 133). Al mateix segle, en un procés criminal lleidatà, un hipotètic bandoler portava «un barret servater pardillo» (Farreny 2004: 62), o «barret de pardillo servater» (id., 68), i els «andadors» dels velluters vestien «robes de setí tenat y barrets de vellut del mateix color», amb motiu de la visita de Felip II a la ciutat de València l'any 1586 (Escartí 1998: 132). Els xiquets portaven barretet (a. 1584-85) (López Terrada 1986: III, 1023). En les constitucions cincentistes del convent de Sant Josep de València es prohibeix que les monges «porten barrets axí com les llegues» (Fuster, 2002: 87), on veiem un esment a barrets femenins. Ja al segle XVII, en la processó del Corpus de 1621, els jurats de València anaven «ab barrets redons, sisanats» (CICA: 2006 - Porcar, «Dietari», f. 364v, 1. 2), i en la de 1629, «ab un barret de raxa redó, sisanat» (id., f. 372 v , 1. 2), mentre que en la processó de Sant Donís de 1598, per la mort de Felip II, anaven de dol, «ab barrets redons de raxa» (id., f. 26r, 1. 3). L'any 1600, el dia de Carnestoltes, penjaren a València dos homes acusats de lladres, «y·ls penjaren ab robes blanques y barrets blanchs. Y estos són los primers que han penjat en Valèntia ab les semblants robes» (CICA: 2006 - Porcar, «Dietari», f. 48r, 1. 9). Portaven barret els eclesiàstics, des de capellans fins a arquebisbes, passant per cardenals, canonges o ministres de la Inquisició ( $c f$. Martí 1994: I, 240, 308, 323; Martí, Serra 2009: I, 225; CICA: 2006 - «Solemnitats» III, p. 18, 1. 8). Al segle XVII, el barret de quatre cantons era propi dels clergues, des de l'arquebisbe de València fins a capellans i dignitats, com els cardenals o els xan- 
tres (CICA: 2006 - Porcar, «Dietari», f. 171r, 1. 7; f. 214r, 1. 14; f. 215r, 1. 10; f. 235r, 1. 8; f. 492r, 1. 4).

Per tant, amb aquests exemples, $\mathrm{i}$ amb altres que es podrien citar, veiem com el barret era usat per membres d'estaments socials molt variats, i en ocasions molt diverses, i que aquests eren de teixits, formes i colors diferents, i podien dur distints ornaments. També el capell presentava «una gran diversitat de formes i de materials», i el portaven «tots els estaments socials» (Maranges, 1991: 57). Vegem un parell d'exemples medievals que il-lustren l'ús de barret i capell com a objectes diferents: «Adés porten caparó en lur cap, adés tovaylola, adés xapellet, adés vel; adés paternostros, adés correge; adés capell de vebre, adés barret» (CICA: 2006 - Metge, «Somni», p. 264, 1. 4), «Item, pallissers ab capells e barrets de diverses pells, ab lur panó» (CICA: 2006 - «Solemnitats» II, p. 259, 1. 11).

Però capell modernament ha acabat envellint-se, tret del balear, ${ }^{19} \mathrm{i}$ «a la major part del Principat» (Veny 2009a) ha estat substituït per barret, que ha modificat el seu sentit primitiu, per significar 'capell, cobricap amb ala', valor que el $D C V B$ no documenta fins Narcís Oller, però que, com veurem, segurament ja era conegut temps arrere. ${ }^{20}$

A més, des de ben antic, capell ha patit la competència del castellanisme sombrero, documentat en català des del darrer quart del segle XV: ${ }^{21}$ «Item, ffranés ab llur panó, vestits tots ab mantos de tela blava sembrats de argentaria, ab capells o sombreros als caps» (a. 1481) (CICA: 2006 - «Solemnitats» III, p. 340, 1. 17), «I. sombrero guarnit... VIII sous» (a. 1485) (Colón 2011a: 94), i en les Regles d'esquivar vocables es rebutjava la variant sembrero, però per admetre sombrero (Colón 2001), mot que, segons Colón (2001), s'estén en català al segle XVI; ${ }^{22}$ de manera que, tot plegat, ha convertit capell en un terme obsolet en la major part de la llengua. ${ }^{23}$

${ }^{19}$ Coromines (DECat, II, 527), citant fonts de principis del segle XX, diu que capell «resta usual en algun àrea extrema del nordest i nordoest: sembla ser encara vulgar en parlars ribagorçans (...), però sobretot a les Illes»; tanmateix, Veny (2009a: II, 73) en l'ALDC ja només el localitza en balear. ${ }^{20}$ Segons Coromines (DECat, I, 681-682), l'evolució al nou sentit de barret «es degué fer especialment a través dels cobrecaps o lligadures usats per partides de guerrillers, miquelets i bandolers, i pels seus adversaris de les esquadres».

${ }^{21}$ Segons Veny (2009a: II, 73), primer sombrero «s'hauria aplicat als capells d'ales molt amples».

${ }^{22}$ L'extensió de sombrero anava unida a la devallada de capell, ja des del segle XVI. Així, en el Libre de Antiquitats de la Seu de València només apareix capell en una ocasió, l'any 1524, per referència a un clergue ajusticiat per agermanat: «li posaren una cadena al coll hi.l despullaren en camisa, y capell y panyos los confrares dels Ignocents, ab les mans ligades y crucifixi y sos capellans, com als altres sentenciats» (Martí 1994a: I, 89); en la resta del llibre es documenta sombrero, aplicat també al vestuari litúrgic dels clergues. Però capell encara pervivia al segle XVII, com el veiem en el llibre de comptes del palmiter i passamaner Miquel Ferrer (1612-1634): «La dona que fa los capells de fil blanc» (Mandingorra 2007: 28), «tinc rebut a este conte una dotsena de capells fins i altra de comuns i micha dotsena de balones» (id., 47), «capells fins comuns» (id., 57); i en sentit figurat, posar capell (a algú) 'atorgar-li mala fama, anomenada deshonrosa': «Y si trau a plasa deffecte algú o falta de altri, estiga sert que, per lliure que d'elles se trobe, no faltarà qui li posse 
En el Vocabulari català-alemany de 1502 figuren com a sinònims, en la mateixa entrada, capel o sombrero. Hut, diferenciats del bonet. Haublein (Barnils, 1916: 57). En el glossari del barceloní Pere Badia a les Introductiones latinae de Nebrija (1505) figura «pileus. barret o caparusa», «sombrero. Galerus», i capell (CICA: 2006, p. 66, 1. 89; p. 69, 1. 61; p. 115, 1. 55); també Pou (1575: 198) diferencia el sombrero. Galerus vel galerum, el sombrero de sol. Petasus, i el barret o gorra. Pileus, així com el barretet de grana per dormir. Pileolus purpureus ad dormiendum. Igualment, al segle XVII, Font (1637) diferenciava el barret de capellà. Pileus (p. 48), i el sombrero. Galerus, juntament amb el sombrero de grans faldes. Petasus (p. 304), mentre que capell tenia altres usos: capell de capa. Cucullus; capell de dona. Reticulum. Capilare. Mart (p. 65). Torra (1653) és el primer a col-locar en la mateixa entrada barret, gorra o sombrero. Pileus, ei, pileum, galerus, petasus, ${ }^{24} \mathrm{i}$ identifica diferents tipus de barrets: barret natural. Pileum naturale; barret de palla o gira-sol. Umbela; barret de cuyro. Cudo; barret de capellà. Pileus quadratus sacerdotum (pp. 88-89), mentre que capell té altres sentits: $c a-$ pell, mantellina o vel de dona. Plagula, rica, ricula; capell o caputxa de capa. Cucullus; capell de confort. Pileus interclusus; capello o capell de cardenal (pp. 128-129). Ja a finals del segle, Lacavalleria (1696: 81, 962-963) sembla considerar barret i sombrero sinònims, ${ }^{25}$ recull capell aplicat només a les dones: capell de dona (p. 130), i afegeix la veu barretina «hic pileus», amb la variant barretina per a dormir.

Per tant, veiem en els diccionaris i glossaris catalans dels segles XVI i XVII una evolució en aquestes veus, des de la diferenciació original dels mots barret i sombrero, fins a la seua identificació en una mateixa entrada, o com a sinònims, al llarg del segle XVII, i en Lacavalleria es troba per primera vegada

capell, que no li serà fàcil en sa vida llevar-se'l» (Marí 2010: 56), que deu ser també el sentit amb el qual el feia servir Morlà: «Si el servix una ama jove, / dos mil malícies lo noten, / i, ab no ser dona, un capell / en lloc de barret li posen» (Ferrando 1995: 179), en la crítica del poeta a les ames dels capellans, i recordem com aquest sentit el recollia també Sanelo. Així mateix, en provençal antic (portar, avol, croi, mal, orre) capel '(avoir une mauvaise) réputation', en francés mitjà chapeau 'renommée', $\mathrm{i}$ en francés modern mettre un chapeau sur la tête de 'nuire à la reputation de quelqu' un', se donner un mauvais chapeau 'nuire à sa propre réputation' (FEW, II / 1, 288-289).

${ }^{23}$ En la decadència de capell 'peça que cobreix el cap', a més de la interferència castellana, degué influir l'homonímia amb capell 'coberta protectora de forma oval de molts insectes', i potser també amb capell (ardent). A la segona meitat del segle XV, Jaume Roig fa servir el sintagma capell de cap: «Per mortallar, han a comprar capell de cap, camisa, drap, de la botigua» (CICA: 2006 - Spill, 1. 6956), possiblement per evitar possibles ambigüitats.

${ }^{24}$ A més a més dedica una altra entrada a sombrero. «Pileus, ei, pileum, ei, galerus, i. De grans ales o pollaco. Petasus, i» (p. 602-603).

25 Així, barret. «Sombrero. Hic galerus, ri. Hic pileus, lei»; sombrero. «Barret. Hic galerus, hic pileus, hoc pileum». Inclou els següents tipus de barrets: petit barret, barret de conseller, portant la gramalla, i barret de quatre corns; i les següents varietats de sombreros: petit sombrero, sombrero rodó de curtes ales, sombrero de dona de grans ales y copa petita, sombrero de palla i sombrero greixós. 
en els diccionaris el derivat barretina. ${ }^{26} \mathrm{D}$ 'altra banda, capell apareix com a sinònim de sombrero al principi, i després resta restringit a alguns usos especialitzats. $^{27}$

Els diccionaris del segle XIX del Principat continuen identificant barret i sombrero, i assenyalen la decadència de capell. En Belv. barret figura com a entrada secundària per relació a sombrero 'Galerus, pileus', així com la locució «digas-li barret, digas-li sombrero. Olivo y azeytuno, todo es uno», que il-lustra la sinonímia dels dos mots; per la seua part, capel o capell. «ant. V. barret», figura com a antiquat, a excepció d'algun ús especial: «capell, el que.s posa a las criaturas; capell, el que·s posa al falcó y altres aucells ab què.s cassa; capell, el que.s posa de part de dintre en la punta de las sabatas; capell, el que.s posa per part de fora en la punta de las sabatas per adobar-las». El diccionari Quintilingüe (1839), a diferència de l'anterior, dóna preferència a barret sobre sombrero, com a mots sinònims, i inclou capell com a antiquat, amb el sentit de 'barret'. Labèrnia (1839-40), com Belv., en l'entrada barret remet a sombrero 'abrich del cap, compost de una copa ab alas alrededor, y és de diferents figuras y materials', i en l'entrada capel a barret.

En canvi, els diccionaris valencians del segle XIX distingeixen el barret $\mathrm{i}$ el sombrero, com a objectes diferents, però coincideixen amb els catalans a con-

${ }^{26}$ El mot barretina 'barret de forma llarguera' es documenta des de 1565 (DCVB, DECat, I, 683). El $D C V B$ no el registra en valencià, però també hi era conegut: al segle XVIII, el trobem usat entre militars: «Anava en primer lloc lo capità (...), y anava-li un poc davant el mochillero que portava la vengala, qui ab sa barretina y rodella li parava y fea cara a cada tro. Seguien-lo después los soldats» (CICA: 2006 - Esplugues, «Memòries» I, p. 79, 1. 38), «em planta una barretina / bigarrada, y diu: «Guapo hombre, / en tres años oficial»» (Martí 1997: 386), «-Tirant-los del mur avall / als soldats. / -Si eren de bulto. / -De bulto? Com mon germà, / si portaven barretines / i botins!» (Martí 2008: 260), els soldats cristians, en la representació festiva de la lluita entre moros i cristians; la duia un advocat: «Va un home a casa un lletrudo, / ab son negoci en la mà, / y allí veu al so albocado, / en sa cadira sentat, / ab sa bata y barretina» (Carles Ros, Paper graciós, polític y entretengut per a el desfrés de les Carnistoltes, contrafent als llauradors de la horta. De la molinera, s. a., p. 3), i els infants d'edat escolar: «Ya està en la escola. Que risa! / Espenta a hu, moz a l'atre, / a este les greñes li estira, / a aquell de coz o patada / l'emboca dins de la cuina, / (...) y a un atre / li encala la barretina» (Joan B. Escorigüela, Colección de valencianas poesías y castellanas, Biblioteca Valenciana, ms. 421, p. 75). Escrig (1851) recollia barretina, com a sinònim de barret, d'on passà a $E s c L l$. Però per aquestes dates, últim quart del segle XIX, segurament era ja un mot inusual en valencià, i per això $M G a d$ l'inclogué però amb la marca de cat., això és, de mot propi de Catalunya. Segons Coromines, «el nacionalíssim» barretina reemplaçà aviat l'antic barreta 'cobricap fluix' $(D C V B)$, que documenta l'any 1429; trobem barreta encara a la segona meitat del s. XVI ( «E los hòmens, axí com se trobaven, sens sombreros ni barretes e mig despullats, se n'exien per defora de la vila», a. 1568, Escartí 1998: 119), però ja no més enllà, ni el recullen els diccionaris catalans dels segles XVII, XVIII i XIX. Barreta es coneix encara en alguerés, amb el sentit de 'barretina' i de 'gorra de dormir', on molt probablement ha estat afavorit per l'italià berretta (cf. Corbera 2000: 142).

${ }^{27}$ En les Tarifes catalanes de 1683, 1698 i 1704 apareix barrets de feltre, barretines (barratines, barretinas) de seda, de llana, de agulla de llana i de vellut, i sombreros que entran (o que vénen) de fora regne. 
siderar generalment capell un arcaisme. ${ }^{28}$ Al segle XVIII, Carles Ros (1771: 16) corregia el castellanisme sombrero pel gal-licisme japeu (això és, xapeu), i el derivat sombrerer per japehuer, ${ }^{29}$ i no per capell, que devia ser ja un mot rar al seu temps. ${ }^{30}$ En Sanelo figuren en entrades diferents barret (i varret) 'birrete. Pileus' (Gulsoy, 1964: 80, 217) i sombrero (p. 204), i, amb sentits diferents, capell 'capillo', 'ponerle a uno tacha o hacerle injuria', capell de ferre 'armadura de cabeza' (p. 85, 90), aquest darrer segurament un arcaisme, com en Carles Ros (1739: 39-40). Escrig (1851) recull barret 'gorra, gorro', el barret o espècie de solideu en orelles 'becoquín', i, d'altra banda, la variant adaptada sombrer 'sombrero' ${ }^{31}$ i, amb el mateix sentit, capell 'sombrero, por

${ }^{28}$ En efecte, amb la decadència de capell i l'entrada de sombrero, el mot barret continuava designant en valencià un objecte diferent d'aquest, com veiem en aquest text de principis del segle XVII: «Y és la primera volta que se à accostumat de nostros temps, en València, portar los andadors sombreros y no barrets blaus, com accostumaven» (CICA: 2006 - Porcar, «Dietari», f. 217r, 1. 10), el barret podia dur-se davall del sombrero, com veiem en el mateix dietari de Porcar, en el vestuari de dol d'un canonge valencià: «Y lo de[g]à de Morvedre, que era son fill, y canonge, don Christòfol Frígola, anava primer, ab gramalla llarga rosegant, y ab barret redó y sombrero sobre lo barret gran» (a. 1599) (id., f. 45r, 1. 1), i segurament també en aquests versos, referits al catedràtic de teologia Joan Martí Cordero: «No s'à trobat / en la pastura / la vil criatura / mestre Cordero, / ab son sombrero / e barret fort» (a. 1586) (Furió 1999: 121).

${ }_{29}$ Actualment xapó 'capell' (segons Veny 2009a: II, 73, del fr. chapeau) «conviu en algunes localitats rosselloneses amb barret», però sembla que aquest tipus lèxic en altre temps tingué una major extensió en la nostra llengua. Així, el mot xapeu es documenta també, al segle XVII, en el valencià Morlà: «A penes lo divisí / quan me lleví lo xapeu / i, fent-los mil cortesies» (Ferrando 1995: 88), i abans el va usar Ramon Muntaner, en to despectiu, per referència al francés Carles de Valois, «rei del xapeu» (cf. DCVB, DECat, IX, 447; Maranges 1991: 59); en gascó es coneix també el gal-licisme chapèu, juntament amb el patrimonial capèt (cf. Lespy, Raymond 1970: 169; Palay 1974: 197, 226); del gascó, chapeu degué passar a l'aragonés (Nagore 1994: 133); és també d'origen francés el castellà antic chapeo 'sombrero', documentat des de finals del segle XV (veg. Varela 2009: 847-851), així com el portugués chapéu, registrat també des del segle XV (Machado 1987: II, 131). La forma chapó apareix amb prou assiduïtat en textos populars valencians del s. XIX i principis del XX, on sol designar un capell de moda, elegant: «el tio del chapó» (Balader, Al sa y al pla, València, 1862, 21), un petimetre, «(A que li astaque el chapó?)» (Liern, Amors entre flors y freses, València, 1861, 26), «y a voltes pasa carpanta / per estrenar un chapó» (Iranzo, en Tipos d'auca, València, 1878, 34), «Pués si fa una cantonà, / y en alguna habitasió / s'obra l'aigua, en lo chapó / n'empoma una llibrellà» (Roig, en Tipos d'auca, 1878, 159), l'agüelo verd, «Tonet (...) que agarra la blusa y el chapó» (Cidon, L'agüela, València, 1913, 20); en algun cas hom es refereix explícitament al seu origen francés: «el chapó és pròpit de Frànsia» (El Cullerot, Alacant, 23, 1897, 2); la variant chapón en el castellà farcit de valencianismes de Constantí: «aquí en la frente / se notarán las señales / del chapón; le viene estrecho, / y en dos blaüres pintaes» (Fuster Llana, El nano de la falla, València, 1894, 15). Anàlogament, en francés el chapeau «est devenu au XIX ${ }^{\mathrm{e}}$ siècle un signe d'appartenance sociale à la bourgeoisie, par opposition à casquette» (Rey 2001: 701).

${ }_{30}$ Inclou, però, capillo que corregeix «por casquet» (p. 8).

${ }^{31}$ La variant adaptada sombrer no sol aparéixer en els textos valencians populars del segle XIX, però la trobem en algun autor de principis del segle XX, segurament conscient, com Escrig, de l'aspecte massa castellà de sombrero: «xaleco despenjat i un sombrer garsejat» (Thous, Hernández, ... iM'he deixat les espardenyes!, València, 1921, 8), «botins de color, sombrer fregoli amb una plometa darrere» (id., 15), «Baixa de la falla Pepico. És un corruco amb meleneta, sombrer d'ala ampla, xalina i la fam que li toque» (id., 22). 
adorno que se pone en la cabeza'. ${ }^{32}$ En Rosanes (1864: 9) el barret 'el gorro'; en Cabrera (1868) barret 'gorro valenciano'. EscLl defineix amb més detall el barret 'gorro valenciano. Pieza redonda de tela o de punto para cubrir y abrigar la cabeza. Su forma por lo regular es de manga cerrada por un extremo', ${ }^{33}$ i inclou la locució $n$ 'hi à per a tirar lo barret al foch y deixar-lo cremar 'estar uno para desistir de alguna cosa, si para conseguirla le incomodan mucho. Hay para aborrecer los huevos, o para echar rayos, o para patear el gorro, o para echar el hatillo al mar'. Per la seua part, en l'entrada capell prioritza el sentit de 'capullo', i considera antiquat el de 'sombrero. Prenda del traje que sirve para cubrir la cabeza, y consta de copa y ala', i per a traduir el castellà sombrero inclou sombrero i, com Carles Ros, el gal-licisme xapèu (i japeu), amb les variants xapell i japó. D'una manera semblant en MGad, que introdueix algun canvi en la locució d'EscLl: n'hi pa per a tirar lo barret al foch, y no plegar-lo 'hay para aborrecer los huevos, para patear el gorro, para echar rayos o el hatillo al mar; estar uno muy incomodado y a punto de desistir de una cosa', i sobre capell, que continua qualificant d'antiquat, diu que era un 'sombrero a modo de capucha, que usaban los rústicos'.

Però al segle XVIII el mot que trobem més sovint per referència a la peça de vestir usada per cobrir-se el cap, entre els llauradors valencians, és muntera (i montera). Aquests, en efecte, es recollien els cabells amb la còfia ${ }^{34}$ i damunt d'aquesta duien la muntera: «Damunt de mi, cap sagrat!, / tiraren més de tres lliures, / i els que tenia al costat, / sarpadota per ací, / espenta per l'atra part, / em llevaren la muntera / i la còfia» (Martí 2008: 268); es descobrien, traientse-la, amb un gest de cortesia i de salutació: «Va un home per lo carrer / sempre en la montera en mà, / pensant-se que tots arreu / són grandes de quinta classe» (Martí 2008: 286), «Amorós la saludí, / ab ma montera en la mà» (Ros, Paper graciós, polític y entretengut... p. 5). Cavanilles (1795: II, 140), que ens descriu la forma de la muntera, veia que, a finals del segle XVIII, el seu ús entre els camperols valencians anava restant antiquat: «Cubríanse antes la cabeza con monteras de terciopelo de figura emisférica, con caídas semicirculares una a cada lado; hoy se ven muchos con sombreros gachos y gorros catalanes, ${ }^{35}$ alterando así el vestido nacional». Era, doncs, una mena de casquet que cobria el cap, amb caigudes als costats, i sense ales, com el barret. ${ }^{36}$

\footnotetext{
${ }^{32}$ En aquest mot, però, inclou com a primera accepció 'capullo, por la obra del gusano de la seda'.

${ }^{33}$ En Los valencianos pintados por si mismos (València, 1859, p. 11), obra de l'època de Bernat i Baldoví, es descriu el barret dels llauradors com «un gorro encarnado, idéntico al barrete tunecino». ${ }^{34}$ Sobre la còfia veg. Puig Escoí (2002: 103), segons el qual el seu ús anava lligat al costum masculí del segle XVIII i primeries del XIX a portar els cabells llargs, i «a primeries del segle XIX», en desaparéixer aquest costum, desaparegué l'ús de la còfia entre els homes, substituïda pel mocador.

35 En el Almanaque de Las Provincias per a 1902 (p. 156) hom identifica el «gorro catalán» de Cavanilles amb el barret.

${ }^{36}$ Veg. la fotografia reproduïda per Puig Escoí (2002: 58).
} 
Al segle XIX, sobretot als primers anys, continuem documentant en textos valencians populars el mot muntera (montera), per relació a llauradors, però en el conjunt de la centúria amb molta menor freqüència que al XVIII, ja que ara el terme que predomina és barret. Bernat i Baldoví, l'any 1844, encara el feia servir, però amb una connotació d'antigor: per referència a un «retor d'aquells que s'estilaben in illo tempore, és dir, de polsereta blanca y montera de tersiopelo» (D 111), i a «un alcalde de muntereta», d'un «poblet» d'Alacant ( $D$ 179), parlant també de temps passats. És més fàcil trobar-lo al principi del segle XIX: «en la montera en la mà, / li va dir (...)» (Martí 1991: 155), «En la montera en la mà / es diu això» (Coloqui trilingüe... entre Macià el Parlador y.l mestre d'escola d'un poble de l'Horta de València, València, Oficina del Diari, 1809, p. 1), «Que tu no sabries dir-li / al rey, la montera en mà, / quatre coses en honor / de València?» (Chilo y Pacalo, llauradors de l'Horta, marcharen y arribaren a Chirona el dia 23 de marz, en el que fon la entrada tan desichada del nostre rey Don Fernando, València, Francisco Brusola, [s. a: 1814], p. 3), «Punt en boca, / sombrero i montera en mà, / que eixe nom tan soberano / aterra al més obstinat» (a. 1802) (Martí 2008: 335), «Qué delícia pasejar-se / tots per mig de l'Alameda, / vitorejats ab veu alta, / y en alt sombrero o montera!» (Memòria dels obsèquis fets per Valencia à sos reys y real familia en 1802, València), en els dos darrers exemples juntament amb sombrero, com a objectes diferents, i també al costat de barret, designant segurament objectes distints: «Les campanes voltechant, / tots llevant-se les munteres, / tirant els barrets en alt» (Colecsió..., 71), i, l'any 1801, la duia l'intendent de València Jordi Palacios, que per això era conegut amb el malnom de Muntereta (cf. Sanchis Guarner 1972: 322-323), la qual cosa prova que, encara a principis del segle XIX, no era exclusiva dels llauradors. Però més endavant ja resulta més rar trobar-la. Encara utilitzava el mot Escalante (I, 228), per referència a Pepe, un personatge tradicional, de poble, major, fester i un poc atrotinat: «-perquè así en cada cuet... / L'añ pasat micha muntera / me cremaren, y el colom / me s'escapà. / -Bona feta! / (...) Si no anara fent chumensos...».

En el DCVB muntera 'capell d'ales amples que s'usava entre els segles XVII i XIX', que documenta en 1690, i la variant montera, l'any 1917. No figura en el $D E C a t$ ni en el $D A g$., per referència a una peça per cobrir el cap; però el DECat $(\mathrm{V}, 839)$ inclou l'adjectiu munter 'salvatge', derivat de munt, documentat des dels segles XIII i XIV, cabra muntera, cabró munter, ascona muntera (aquest també en el $D A g$.), i com a substantiu munter 'caçador encarregat de cacera major', des del s. XIV ( $c f$. també el $D C V B$ ). Referit a una peça de roba per al cap, documentem per primera vegada montera a mitjan segle XVI, en l'inventari dels béns del comte d'Oliva: «una montera de vellut pardo, forrada de tela parda» (a. 1550) (Felip 2000: 332), «un papafigo y montera» (id., 333). Un poc abans, en el Dietari de Jeroni Sòria (1960: 64), apareix barret montero: l'any 1521, quan el cap agermanat Vicent Peris desembarcà en la platja de València, «donà lliurea a XXV escopeters per patges; e-ls féu capotins a la viscaïna, blanchs de drap, e barrets monteros». Al darrer quart del s. XVI, es troba montera per referència a un cobricap 
principesc: «lo dit sereníssim príncep estave vestit ab roba de setí encarnat ab enforros de tela de plata, y al cap una montera com lo capot, ab ses botes blanques» (a. 1585) (CICA: 2006 - «Solemnitats» VII, p. 48, 1. 23); al segle XVII, la montera formava part del vestuari litúrgic d'un pertiguer de la Seu de València: «al pertiguer Pedro Ruíz se li féu roba, lloba y montera, sotana y manteu de vayeta» (a. 1611) (Martí 1994: I, 281); la trobem en un bandoler: «Baixà la vella, y entrà un home a soles, ab una muntera y unes bigoteres posades que li prenien tota la cara» (Escartí 1999: 262), i la duia el príncep Don Caliu en la comèdia paròdica $L a$ gala està en son punt, quan aquest personatge es queixa del vestuari que porta, impropi de la seua categoria social, entre altres coses perquè, en comptes de sombrero, es cobreix amb muntera: «¿Com puch de aquesta manera / anar devant de persones, / ab andrajos per balones, / per espasa una granera, / per sombrero una muntera, / per capa un tros de flaçada, / per camisa delicada / una sarpellera grossa?» (Morell 1986: 124-125).

Montera figura en Lacavalleria (1696), com a sinònim de gallarussa: gallarussa o montera. «Hec galea, ae». Després el recullen els diccionaris del segle XIX, com Belv. (montera. Montera. Pileum), Labèrnia ('casquet rodó ab una volta cayguda a l'entorn per a tapar las orellas y front') i el Quintilingüe, sempre amb o, montera. Els diccionaris valencians del XIX donen preferència a muntera sobre montera; és l'única variant recollida en Escrig, i la preferent en EscLl i MGad, si bé aquest darrer ens informa que al seu temps era una peça poc usada: «especie de gorra de paño o terciopelo, para abrigo de la cabeza; es de varias hechuras y se usa ya poco». El mot montera 'prenda para abrigo de la cabeza que generalmente se hace de paño’ és també castellà, on es recull des del segle XV (Alonso 1986: 1409), i el recullen els diccionaris des de finals del XVI (Percivale 1591). ${ }^{37}$ Coromines $(D C E C H, \mathrm{IV}, 131)$ inclou el castellà montera entre els derivats de monte; igualment, el català muntera / montera podria procedir fonèticament, com el masculí munter i l'adjectiu munter, $a$, de munt (mont), tenint en compte la dualitat existent des d'antic entre $u$ / $o$ en els derivats de munt (llatí MONTE), sobre la qual vegeu el DECat (V, 835-843) i Mas, Monjo (2001: 132), però altres arguments ens fan dubtar de l'autoctonia de montera, aplicat a una peça de roba per cobrir el cap. ${ }^{38}$

\footnotetext{
37 En els diccionaris castellans antics la montera sovint es relaciona amb el camp, amb els munters o els pagesos, des d'on s'estendria a l'ús urbà. Així, en Diego de Guadix (1593) 'suerte de caperuça de que usan en España para el campo' (montera o caperuça montera), en Rosal (1601) 'caperuza de monte'; segons Covarrubias (1611) tindria l'origen en la munteria, i d'ací es generalitzaria: 'cobertura de cabeça de que usan los monteros y, a su imitación, los demás de ciudad'; alguns diccionaris del s. XVIII fan esment a l'ús de la montera per part dels caçadors i els homes de camp: en Stevens (1706) 'a cap, such as hunters, or countrymen wear', en Terreros (1787) 'abrigo y adorno para la cabeza, mui usado de los paisanos' ( $c f$. NTLLE, NTLE).

38 En efecte, en els textos medievals catalans es troba munter, muntera, com a adjectiu i com a substantiu ('caçador'), sempre amb $u$, i la forma amb o, montera, per designar un 'objecte de tela per cobrir el cap', no es documenta fins al s. XVI, amb la mateixa forma que en castellà. A més, en la primera documentació que en trobem, barrets monteros, presenta una morfologia clarament
} 
Tornant al barret, Marc Antoni d'Orellana (1731-1813) deia que l'ús dels barrets populars s'havia envellit al seu temps, davant la puixança dels sombreros (192324: II, 594). Això, si era així, devia ser aplicable a l'ús urbà, o bé Orellana feia aquesta afirmació pensant en les munteres, descrites per Cavanilles, ja que en els textos valencians populars del segle XIX es documenta sovint barret com una peça de roba característica dels pagesos, els quals, de fet, són anomenats metonímicament gent de barret: «encara que tots són chent de barret, camalets, espardeñes y calses de trabeta» (El Mole 1837, I, 236); en aquest altre text, del darrer quart del segle, trobem el barret juntament amb altres elements propis del vestuari del camperol: «Seré tartanero (...). / El dia que yo barataré / els saragüells d'agramar, / chopetí, manta, barret, / faixa, espardeñes d'espart, / per uns pantalons de llana, / casaca, botes (...), / gorra» (Burguet, Propietaris y colonos, València, 1876, 27), diu el llaurador Quico, disposat a canviar d'ofici. Però aquest no era l'únic tipus de barret que documentem en els textos valencians de l'època. Estava el barret negre, de moda: «Aquell que no porta gorra / o barret negre hu fa mal; / no és home com ha de ser, / y per goleta el tindran. / Com és moda afrancesada, / la tenen per cosa gran. / Com és moda afrancesada, / la tenen per cosa gran» (a. 1816) (Branchat, Conversasió que tingueren Pocarropa y Pocodinero en una taberna, BUV, ms. 661, p. 88), el barret de dormir: «Pa la sipela, una seba / porreta lligà.l barret / de dormir o al matalap» (Cester, en Tipos d'auca, València, 1878, 53), o el barret de loco: «Vachen campanes al bol, / (...) ixquen nanos y chagans, / (...) tire's tot per la finestra; / anem tots a l'Hospital / per cota y barret de loco» (Branchat, Conversasió que tingueren el tio Bernat..., p. 55). ${ }^{39}$

El sombrero, per la seua part, designa en aquests textos populars un tipus diferent de lligadura, que portaven els petimetres, o els mateixos llauradors quan anaven mudats o a festejar: «en capa y sombrero» $(Q 21)$, «còfia de seda o de grana, / (...) pechera en molt almidó, / (...) / y el sombreret de cantó» $(F 7)$, en el vestuari del llaurador per anar a festejar; «Casimiro (...) es lleva el disfràs, deixa

castellana, i funciona com a qualificatiu d'un determinat tipus de barret, com en la caperuça montera de Diego de Guadix (1593). Fora del castellà, és portugués: monteira 'carapuça de montanhês' (Novo Aurélio); en italià, on és considerat un castellanisme, es conegué als segles XVII i XVIII montièra (montèra) 'tipo di copricapo di panno o anche di velluto', en sicilià muntera 'berretta da bambini' (Battaglia 1970-1999); no es registra en francés ( $F E W$ ), i en occità té un desenvolupament escàs; només els diccionaris del segle XVIII recullen un mountiero 'sorte de boune' (Pellas 1723), 'tapebord, sorte de bonnet que l'on portoit sur les vaisseaux' (Dictionnaire de la Provence et du Comté-Venaisin, 1785), que figura també en Mistral (1979: II, 368), el qual el relacionava amb el cast. montera 'gros bonnet de drap', i el considerava antiquat al seu temps: 'tapabor, sorte de bonnet que l'on portait autrefois sur les vaisseaux'. Per tant, veiem que la seua major vitalitat, com a nom de peça per cobrir el cap, correspon al castellà, des d'on s'ha estés a altres idiomes, com l'italià.

39 Ja al segle XIV apareix el birret en el vestuari dels bojos: «E lo dit En Bernat Comte és hom vell desmamoriejat, e los prohòmens de Cullera, per la dita rahó, en unes festes de Nadal li feren corona e li meteren un birret al cap, e fehien-lo anar en una barqua en exut per la vila, ab gonella enfresada que li vestiren, axí com a hom orat» (a. 1381) (CICA: 2006 - Sueca, p. 154, 1. 10). 
el sombrero» ( F 17), Casimiro anava disfressat de lechuguino; «El galan de la señoreta se quedà en lo sombrero en la mà» $(T 9)$. El sombrero formava part del vestuari de moda, sovint d'origen francés: «Puix què direm dels sombreros; / si no són de Perpinyà / o de atra terra de Fransa, / ya no els vol ningú comprar» (Branchat, Conversasió que tingueren Pocarropa..., p. 88). En el folklore ens han arribat referències a diferències socioculturals per relació a l'ús de tots dos objectes. Així, en la següent cobla, recollida per Francesc Ribes i Manuel Sanchis Guarner a l'Alcora, conviuen barret, a Almassora, i sombreret, a la més senyorívola Borriana: «En Castelló porten gorra, / en Almassora, barret; / en Vila-real, mocador, / i en Borriana, sombreret» (ap. Meseguer, 2009: 44); en una altra es destaca com es mudaven, amb sombrero, els homes de la Vall (Valldigna) per anar a festejar: «Per a saber festejar / ningú com els de la Vall, / que es posen capa i sombrero / i es muden de dalt a baix»; o, encara, un moliner es distingeix socialment amb l'ús del sombrero: «Dominguet el moliner / s'ha fet molt pinxo i trempat, / porte sombrero i bengala, / rellotge i jaleco amprat» (Puig Escoí 2002: 60, 283).

Veiem, doncs, que a Catalunya, amb la decadència de capell, va ocupar aquest lloc barret, que desplaçà el seu significat originari, i el castellanisme sombrero; mentre que en valencià capell fou substituït per sombrero, i barret, i també muntera, mantingueren per regla general el seu valor tradicional, fins que la decadència dels referents suposà l'envelliment progressiu dels mots. Actualment la restricció de barret s'ha accentuat en valencià, unida a la desaparició progressiva del vestuari tradicional dels llauradors. ${ }^{40}$ Segons les dades de l'ALDC, amb el sentit general del cast. sombrero, només fou arreplegat el mot barret a l'Alcúdia de Carlet, com a forma arcaica, juntament amb sombrero, i a Torís amb el sentit de 'boina' (núm. 201 «El barret»), si bé conserva una major extensió amb el valor d' 'estrenyecaps' (núm. 200), i en alguns llocs es coneix barret amb el sentit de 'gorra de cop' (Alzira, Cabanes de l'Arc) ${ }^{41}$ valor que es retroba en alguns punts de Catalunya (núm. 199). ${ }^{42}$

Bona prova de l'ús tradicional de barret en valencià n'és la presència àmplia en la fraseologia i la paremiologia: a on no hi ha cap no cal barret (Llombart, El pare Mulet... y Bou Solt, València, 1877, 106), ${ }^{43}$ a on hi ha barrets no valen capuches (Alberola 1928: 6); a la rum-bum, barret de fum, el que s riurà la pagarà (id., 11); en temps de fret val més una gorra qu·un barret (id., 100), quan fa fret

\footnotetext{
40 A principis del segle XX, en l'Almanaque para 1902 de Las Provincias (p. 156), es deia que el barret i els camalets ja havien desaparegut del vestuari dels llauradors de l'Horta, si bé aquests encara conservaven el mocador, «con que aún ciñen la frente muchos de nuestros labradores», i la manta.

${ }^{41}$ Amb aquest sentit també es coneix barret 'gorra de palla amb un sortint de secció semicircular tot al voltant per a evitar les criatures de rebre cops al cap' a Alcalà de Xivert (Verge 2008: 220).

${ }^{42}$ Colomina (1991: 111) constatava l'ús encara de barret 'capell de punt o de llana' en alguns pobles de la Marina Baixa entre les persones grans.

${ }^{43}$ En Alberola (1928: 7) a on no n'i ha cap no cal barret (o sombrero), en Carles Ros (1736: 58) hon no hi à cap no cal sombrero.
} 
val més una gorra qu·un barret (id., 224), o en temps de fred val més capa que barret (Sanxis 2011: 74); justet li venia a l'agüelo el barret (Alberola 1928: 133), lo mateix té barret blanc que barret negre (id., 153); tants caps tans barrets (Orellana 1923-24: I, 178), molts caps y pocs barrets (Ensisam, 444), o masa caps per a tant p [o]cs barrets (Alberola 1928: 163); ni per calor ni per fret, no.t lleves la capa ni el barret (id., 178); qui de canyes fa flautes y de flautes fa cabal, un barret y a l'hospital (id., 232), per referència als barrets dels bojos; posar-se alt de barret 'airar-se, irritar-se (algú que s'ha sentit ferit en l'amor propi)': «-que talle claus d'a diner, / y per a no fer-ne una, / no sé quin Déu em deté. / M'han acusat les coranta, / així com qui no diu res. / (...) -Sí, però les parets ohuen. / No·t poses alt de barret, / que no mos convé a mosatros / escamar el galliner, / pués si no se n'aniria / tot al patí del bordell» (Alberola, L'amo y señor o Refranera valensiana, València, 1927, 34); fer el barret llarg 'estar xarrant molt de temps': «Ay, chica, me'n vaig, que ya són corrent de huit. Estem fent masa llarc el barret» (Morante, L'alcalde de Favara, València, 1947, 1), ${ }^{44}$ girar-se el barret (a algú) 'posar-se nerviós, enutjar-se' (Segura 1996: 127); tot ve a ser una cosa, menys la cota $i$ lo barret: «Per tot asò un devot pasa / de molt poc enteniment, / que tot ve a ser una cosa / meñs la cota y lo barret» (Martí 1997: 320); o la fórmúla expressiva al cap un barret, deformació jocosa de la locució al cap 'al capdavall, finalment": ${ }^{45}$ «No tinc qui em demane pa, / ni dona que em desinquete / y que.m fasa condenar, / ni cuñades que.m murmuren, / ni sogra en qui pleitechar. / Toro suelto bien se lame, / y al cap, com diuen, al cap / un barret» (Martí 1997: 254), jugant implícitament amb les banyes, com a simbol de l'adulteri, que amenaça tots els casats, «-Li ha costat de dir, / però al cap... / -Al cap... / un barret» (Lladró, La demanà de una nóvia, València, 1858, 27), fent burla de les paraules del seu interlocutor, tots dos rivals per casar-se amb Carmeleta.

Bernat i Baldoví fa servir mots tradicionals que en el valencià popular actual experimenten un procés d'envelliment, en graus diversos, o que reben la competència d'un castellanisme. Així, utilitza el substantiu torcaboca 'tovalló', «que menchen pa (...) en torcaboca al coll o al pit» (D 35), en aquest cas convivint amb el castellanisme servilleta, que Bernat usa amb el verb desplegar: «desplegar la servilleta» (Te 18), «desplegaren les servilletes» (T 105). Segons el DCVB, torcaboca o torcaboques 'tovalló', documentat des del segle XV, actualment és valencià (torcaboca) i mallorquí (torcaboques); però antigament

\footnotetext{
${ }^{44}$ Joaquim Uríos l'explicava de la manera següent: «Cuando la costumbre de llevar barret estaba en su apogeo, las mujeres se encargaban de su confección, y con las agujas en ristre se iban a buscar a la vecina, con quien charlar de lo lindo mientras hacían barret, por lo que el marido solía reprender a su esposa cuando ésta llegaba tarde a casa, diciendo: «Si qu.has fet el barret llarc!» Frase alegórica que todavía se emplea en la actualidad para estos casos» (Buris-Ana 3, 1956, 3).

${ }^{45} C f$. «Yo em casaria a l'instant, / però tinc por que la dona / me visca aixina mols añs, / perquè al cap, del mal el mich; / sí que se pasen treballs / en la vida de fadrí, / però més pasa el casat, / si la dona li viu molt» (Martí 1997: 283), «que al cap mich duro millor està en lo bolsillo del seu amo que en el nostre» ( $S$ 88).
} 
tenia un abast pancatalà ( $c f . D C V B ; D E C a t$, VIII, 581; DAg, VIII, 91). Onofre Pou (1580: 127r) va recollir en la mateixa entrada, com a sinònims, torcaboques, tovallons i servietes «mantile, mantilis»; ${ }^{46}$ en Font (1637) torcaboques figura com a entrada principal, i tovalló com a secundària; Torra (1653) recull torcaboques o tovallons 'Mappa, mantile' en una entrada doble, i en les Tarifes dels preus de les teles y mercaderies de Catalunya del darrer quart del segle XVII figuren tovallons i torcaboques (i torcabocas), de vegades formant parella: «tovallons y torcabocas» $(1683,1692,1698) ;{ }^{47}$ per la seua part, Lacavalleria (1696) només arreplega tovalló «hoc mantile. hoc mantelium, hoc mantelum. Detergendis ad mensam manibus, linteum», i no inclou torcaboques. ${ }^{48}$ Per tant, assistim a la convivència de torcaboques i tovalló en català central al llarg del segle XVII, i al triomf del segon mot, ${ }^{49}$ unida a la decadència del verb torcar en aquest dialecte. ${ }^{50}$ Al s. XVIII Broch (1771: 42) recull només tovallons (cast. servilletas, fr. serviettes), i els diccionaris principatins del XIX inclouen tovalló com a entrada principal, i de vegades única, $\mathrm{i}$ torcaboques com a veu antiquada ( $c f$. Belv.; Roca 1806; Labèrnia; Quintilingüe). Quant a servilleta, no apareix fins a Labèrnia (1839-40), però amb un sentit diferent, com a veu «familiar», i amb la consciència per part del lexicògraf del seu origen castellà: servilleta «lo paper per a limpiar-se en las necessitats majors. És veu purament castellana. Servilleta. Anotergium». A València, on torcar conserva tota la vitalitat, la situació era diferent, car torcaboca (torcaboques) hi era la veu habitual al segle XVII, ${ }^{51}$ i es manté en els diccionaris dels segles XVIII i XIX: És l'única veu recollida per Ros (1764), ${ }^{52}$ per La-

46 Ací servietes segurament era un gal-licisme; per aquelles mateixes dates es documenta per primera vegada en castellà servieta i servilleta, del fr. serviette, $c f$. l'occità antic servieta (veg. $D C E C H, \mathrm{~V}, 244)$, i actualment encara servieta és la forma rossellonesa ( $c f . A L D C$, núm. 375 «El tovalló»), que al gironí Pou devia resultar-li familiar. En l'edició de 1575 del Thesaurus puerilis no apareix servietes: «torcaboques o tovallons. Mantile» (p. 187).

47 En canvi, en la Tarifa de 1547 només apareixia torchaboques.

48 Igualment, en la Tarifa de 1704 figura només tovallons (p. 16).

49 El substantiu tovalló en català antic designava una 'mena de tovalla o tovallola', i, segons Coromines, no es documenta amb el sentit modern de 'peça de tela per usar menjant a taula' fins Onofre Pou (cf. DECat, VIII, 681).

50 Segons Veny (2009a: II, 162), la recessió de torcaboques i de torcar potser s'explica «perquè sovint el mot apareixia dins el sintagma torcar-se el cul». Notem en aquest sentit que Figuera (1840) recollia a Mallorca torcabocas amb el sentit de 'paper, pedàs para torcar-se es derrera', com torcacul, i les expressions torcar-se es derrera i torcar sa merda.

${ }^{51} C f$. «hui li furten lo cendrer, / demà un parell de llançols, / i altre dia lo pagés, / d'allí a poc los torcaboques» (Morlà, en Ferrando 1995: 71), «Y del li que restellaven / per a vels y torcaboques» (1665) (Ferrando 1983: 1042), en inventaris valencians del segle XVII: «una peça de torcaboques» (a. 1616) (Garcia 1927: 252), «11 torcaboques de pallolat», «5 torcaboques alamanceschs» (Martínez Rondán 1984: 65), «dos troços de tela de torcaboques», «dènau torcaboques de texit de cassa» (a. 1655) (Martí e. p.), i en les Tarifes valencianes de 1628 i de 1671, i en la variant tarcaboques, que no sembla un error, car apareix repetida diverses vegades, juntament amb tavallola, tavalloles (a. 1653) (Julià 1921: 332-333), les quals podrien ser dos exemples més de la tendència a la centralització de la $o$ àtona, en aquest cas amb dissimilació respecte a la ó tònica, i possible assimilació a la $a$ de la síl·laba següent (veg. Veny 2009b: 93-113). 
marca (1839) i per Rosanes (1864: 18), i figura en EscLl i MGad, juntament amb servilleta; en canvi, no hi apareix tovalló. En temps de Bernat i Baldoví segurament convivien en valencià torcaboca i el castellanisme servilleta, aquest amb tendència a imposar-se ${ }^{53}$ com finalment ha ocorregut. ${ }^{54}$

El mot més habitual en valencià al temps de Bernat i Baldoví per designar la 'dona que assisteix les parteres' era comare. És el que ell fa servir: «-hasta saber definitivament si el futuro parto de nuestras prosaicas musas serà mascle o femella. -Això la comare eu té de dir» (T 195), i el que trobem habitualment en els textos populars valencians dels segles XVIII i XIX, ${ }^{55}$ i, de fet, ja es documenta als segles XVI i XVII, en textos valencians: «tornaré a dir en esta [lletra] la manera del part: (...) Espantí.m un poc, com era cosa que no u acostumava, enviý per la comare, dix que m'estigés al lit, pux no tenia mal, y que treballàs de dormir» (a. 1534) (CICA: 2006 - Liori i Requesens, Epistolaris, c. 29, 1. 21), «Tingué molt bon part (...), encara que parí sens comare» (CICA: 2006 - Valeriola, «Biografia», p. 177, 1. 29), «per a nomenar qualsevol comare per a efecte de fer visura en la persona de Casilda Menries» (Garcia i Osuna 2003: 289), per verificar si havia estat rompuda y estrupada; i a finals del XV, en Lo somni de Johan Johan (València, 1497) (cf. Veny 1958-59: 110), i comare de bena 'llevadora' en el Procés de les olives (València, 1497) (Miquel i Planas 1911: 363; DAg, II, 216). El DCVB qualifica comare 'llevadora' de valencià i balear, sense documentar-lo, ${ }^{56}$ el DAg (II, 216) el recull en

\footnotetext{
${ }^{52}$ Si bé en un col-loqui seu apareix ja servilleta, el qual és el primer esment que tenim del mot: «dos parells de servilletes, / dos toballes de la taula» (Rahonament y coloqui nou hon se reciten les fatigues y treballs que passen los casats curts de havers, 3 ).

${ }^{53}$ En els textos valencians del s. XIX documentem més habitualment servilleta: «Vegué una taula parada / en servilletes y plats, / culleres de plata fina / y molts menchars delicats» (Coloqui nou entre Pep de l'Orta..., en Cahner, 2002: 229), «Ni tens taula ni toballes; / servilletes, Dios las dé; / tenedors, els cinc apòstols» (Parranda y Bufalampolla vénen del norte, cridats de Cento y Tito, València, 1811, 1), «trahuen torcaboques o servilletes» (Martí Gadea, Ensisam de totes herbes, València, 1891, 472).

${ }^{54}$ Actualment les dades de l'ALDC (núm. 375 «El tovalló») mostren que servilleta pràcticament s'ha generalitzat en valencià, amb les excepcions de tovalla a Vilafranca del Maestrat, tovalletes a Simat (juntament amb servilleta), tovallola a Torremançanes i drap i tovalles a Guardamar, mentre que torcaboques resta com a forma només mallorquina. A Menorca, on també s'ha imposat tovalló, en un inventari de 1704 apareix encara torcabocas (Veny, Massip 2011: 68), però en el vocabulari d'Hospitaler (1869) ja només apareix tovallons, com a equivalent del castellà servilletas. ${ }^{55} C f$. «La comare que va veure / un nas sinse peus ni cap, / enconar-ho no sabé, / ni el pogué tampoc bolcar» (Coloqui nou y entretengut per a riure y pasar lo temps, después de la pancha plena... Coloqui del nas, València, s. a., 2), «Tot asò ho tindreu a punt / dins de un curiós tabaquet, / que la señora comare / ya ho demanarà a son temps» (Coloqui nou molt graciós y entretengut, hon se referixen al peu de la lletra totes les cosetes que dehuen previndre les señoretes abans de parir, $\mathrm{s}$. a., 2), la bolcada, «y ma mare fon comare / de la vila de Canals» (Raonament y coloqui nou a hon li referix un llauró a una valencianeta les moltes gràcies que té, València, s. a., 2), «La comare I (...) duya a la criatura» (Merelo, Un bateig en Burriana, Castelló,1871, 17), «pegant-li pataetes en molt de cuidado a la comare» (El Blua, Castelló, 2, 1892, 2), a més dels exemples que citem en Martí (2001: 195; 2011: 192).
} 
valencià, mallorquí i tortosí (Ulldecona), i Coromines (DECat, V, 479), que el documenta en Martí Gadea, diu que aquest valor es dóna «sobretot en valencià». ${ }^{57}$ Figura en els diccionaris valencians, des de Sanelo, ${ }^{58} \mathrm{i}$ en els mallorquins i menorquins del segle XIX..$^{59}$ L'ALDC (núm. 479 «La llevadora») registra comare en valencià, juntament amb comadrona, així com al Montsià (Ulldecona) i a la franja occidental del català nord-occidental (el Matarranya, el Baix Cinca, la Llitera i la Ribagorça, on comare -la Pobla de Roda- conviu amb comadre-les Paüls-), a més de Mallorca i Menorca.

Mot procedent del llatí cristià commater 'padrina de fonts d'un infant', d'on passa a les llengües romàniques. En castellà, comadre, entre els segles XIII i XV, «llámanse así recíprocamente la mujer que ha sacado de pila a una criatura y la madre de ésta, y por ext., el padre y el padrino del bautizado dan también el nombre de comadre a la madrina», i al s. XV 'alcahueta; vecina y amiga' (Alonso 1986: 723), i amb el sentit de 'llevadora', des del segle XVI. En una de les primeres fonts on es troba és en el Libro del arte de las comadres o madrinas y del regimiento de las preñadas y paridas y de los niños (Palma de Mallorca, 1541) del mallorquí Damià Carbó, on l'autor oposa el cast. comadre o partera al cat. madrina: «Y esta comunmente en lengua castellana es llamada comadre o partera. En lengua catalana se dize madrina. En latín es llamada obstetrix» (ap. CORDE).

Segons Veny (1958-59: 111), en català comare va evolucionar semànticament des de 'madre espiritual que cuida la criatura' a 'mujer que ayuda a nacer al niño'; un canvi semblant, o potser també des de 'dona coneguda, companya o amiga', es produí en castellà, ja que entre comares devien ser habituals aquesta mena de relacions i assistències. En el següent poema castellà d'Al-

\footnotetext{
56 A més d'aquest sentit de comare, el recull també amb els de 'padrina de fonts d'un infant, en relació al padrí o als pares d'aquest' (occ., mall.), doc. Llull; 'padrina de fonts' (Campello, Alacant), 'cadascuna de les dones que acompanyen la padrina en el bateig' (Llucmajor), 'dona veïna o companya d'altres, i especialment dona xafardera, xerraire' (or., val., mall.), doc. sant Vicent Ferrer; 'dona alegre, licenciosa'.

57 Coromines (DECat) recull comare primerament amb el sentit de 'la igual d'una altra dona, de primer quan eren mares totes dues, després entre altres persones adultes d'edat semblant', amb el primer sentit documentat en Llull, i amb el segon en Eiximenis; i afegeix que «sobretot en valencià pren de vegades el sentit de 'llevadora', o el de 'padrina' quan s'esmenta en relació amb el "padrí'», i documenta aquest segon sentit en Jaume Roig.

${ }^{58}$ En Sanelo comare 'comadre o partera' (Gulsoy 1964: 97), i també comares 'padrinas' (p. 94), comare de bateig 'madrina de bautismo', comare de novia 'madrina de boda' (p. 99).

${ }^{59}$ En Febrer i Cardona comara 'comadre, padrina. Commére. Mater lustralis', ' comadre. Sagefemme. Accoucheuse. Obstetrix' (Paredes 2001: 87), en Figuera (1840) comare 'la dona qui assisteix a batisme', 'la qui assisteix a las donas qui van de part', en Unos amigos (1859) comare. «Comadre, madrina. // La muger que por su oficio asiste a la que está de parto. Matrona, partera, comadre». Els diccionaris del Principat del s. XIX no recullen el sentit de 'llevadora'. En Belv. i Labèrnia 'padrina de batejar', 'amiga', i semblantment, en el Quintilingüe 'padrina de batejar', 'la vehina y amiga ab qui altra dona té més tracte y confiansa'.
} 
fonso de Villasandino (a. 1379 a 1425) veiem com les comadres ajudaven les dones en els parts; a pesar que el sentit de 'llevadora' no hi és encara evident, ja s'apunta clarament, a través de la funció d'assistència que es prestaven les comadres en els parts: «La Virgen María, santa criatura, / sola, sin compaña, sin otra comadre, / teniendo a Josep sólo por cofadre, / parió Fijo e Padre sin otra tristura» (ap. CORDE). En textos castellans dels segles XVI i XVII es parla de comadre o partera com a termes sinònims: «en los braços de la partera $\mathrm{o}$ comadre» (a. 1535 a 1552) (Gonzalo Fernández de Oviedo: Batallas y quinquagenas, ap. CORDE), «En viéndome la comadre o partera» (c. 1620) (Lope de Vega: El poeta, ap. CORDE), i en aquest altre d'una comadre partera: «Maia, la comadre partera» (a. 1606) (Juan Alonso y de los Ruyzes de Fontecha: Diez privilegios para mujeres preñadas, ap. CORDE).$^{60}$

La veu madrina 'llevadora', que, com hem vist, Damià Carbó, al segle XVI, considerava pròpia del català, en relació amb el castellà comadre o partera, es documenta amb aquest sentit des del segle XIV (DCVB; Colón 1993: 51);61 el $D C V B$ actualment la recull al Pallars, Tremp, Urgell i Tortosa; Coromines (DECat $, \mathrm{V}, 479)$ diu que resta usual «en valencià i en tot el català occidental», i Veny (1958-59: 111) la registra actualment «a Tortosa y en varios puntos septentrionales de la Cataluña occidental».$^{62}$ En valencià, però, és un mot antiquat, i ja ho era en temps de Bernat i Baldoví, que no el fa servir. Marc Antoni d'Orellana al segle XVIII, ja la considerava una veu antiga, davant de la forma comare, l'habitual al seu temps ( $c f$. Martí 1994b: 136), però al segle XVII encara era usada en valencià, $c f$. «Diumenge, a 23 de setembre 1612, (...) en València, (...) en casa de la madrina Isabet Joan Franca, parí una dona secreta un mònstruo» (CICA: 2006 - Porcar, «Dietari», f. 164r, 1. 14), «Cabildo il.lustre, a qui deu / aquest pres, aquest pobil, / més que a una bona madrina / una dona quan parix» (Ferrando 1995: 83). Així mateix, al segle XVII figuren madrina i llevadora com a sinònims en Font (1637) i Torra (1653), però a principis del XIX, madrina 'llevadora', 'padrina', ja era una veu antiquada en Belv.

${ }^{60}$ En italià, comare, com en català, en castellà i en portugués (comadre) (Novo Aurélio), ha evolucionat a 'levatrice, ostetrica', sentit documentat des del segle XV (Battaglia 1970-1999: III, 341); en francés, des del significat antic de 'marraine d'un enfant par rapport au parrain ou aux parents', commère evolucionà semànticament, per extensió, a altres sentits relacionats, com 'femme avec qui on entretient des rapports familiars, amie, compagne', 'mère, nourrice', 'femme ardie et energique', 'femme bavarde qui colporte les nouvelles' (Imbs 1971-94: V, 1121: 1122; Rey 2006: 815); en occità comaire 'commère, celle qui à tenu un enfant sur les fonts; demoiselle d'honneur d'une mariée; intrigante, femme rusée; jouet d'enfant; amie' (Mistral 1979: 608), gascó coumày 'commère; marraine; nourrice' (Palay 1974: 261).

${ }^{61}$ Colón (1993: 51) afirma que «n'abunden les citacions, i en general es tracta d'exemples valencians».

${ }^{62}$ En l'ALDC (núm. 479 «La llevadora») madrina figura al Montsià, Baix Ebre, Ribera d'Ebre, Priorat i Pallars Sobirà. 
Amb el sentit de 'mare baptismal del fillol', madrina, a diferència d'altres llengües com el castellà, el francés i l'italià, ${ }^{63}$ segons diu Coromines (DECat, $\mathrm{V}, 478$ ), «en català a penes va usar-se» ${ }^{64}$ substituït per padrina,${ }^{65}$ el qual evitava la confusió amb madrina 'llevadora' ( $c f$. Colón 1993: 51). D'altra banda, en la decadència posterior de madrina 'llevadora' en la major part de la llengua moderna pogué tenir algun paper la proximitat formal i semàntica amb padrina 'mare baptismal del fillol', amb el risc consegüent de confusions en conceptes pròxims, si bé, considerant la data avançada en la qual té lloc el decandiment de madrina 'llevadora', és molt probable que hi intervingués la interferència del castellà, llengua en la qual en l'època del canvi el mot madrina tenia habitualment el sentit de 'la muger que tiene a la criatura en la pila mientras la bautizan, o le asiste en la confirmación, [o] la que acompaña a otra que va a tomar estado' (DRAE 1803), i no el de 'llevadora', ${ }^{66}$ i més tenint en compte que en valencià la madrina 'llevadora' convivia amb la forma sinònima comare, que comptava amb el correlat castellà comadre id.

Al segle XIX es va introduir en català el castellanisme comadró, i el cultisme matrona, ja existent des de l'edat mitjana amb altres sentits, es documenta ara amb el valor de 'llevadora'. Aquest darrer, com a sinònim de llevadora, és qualificat per Coromines (DECat, V, 184), que no el documenta, de «vague i pretenciós»; en el DCVB matrona 'dona que té el títol oficial de llevadora', també sense documentació. En Labèrnia (1839-40) trobem per primera vega-

\footnotetext{
${ }^{63}$ En llatí tardà hom diferenciava la matrina 'matrina spiritalis de fonte et confirmatione' de la commater 'mulier dicitur esse ei, cujus filium vel filiam de fonte baptismatis suscepit : vel e contra, mulier commater est illius qui filium suum aut filiam suam de fonte baptismatis suscepit' (Du Cange 1883-87); aquesta distinció, en uns termes semblants, continuà en francés (marraine [marrene] - commère), castellà (madrina - comadre) i italià (madrina - comare) antics (cf. Imbs 197194; Battaglia 1970-99; Alonso 1986; Rey 2006).

${ }^{64} \mathrm{El}$ recullen amb aquest sentit Torra (1653), remetent a padrina: madrina. Del que.s bateja. Vide padrina, i més tard Belv.: madrina ant. V. padrina. Segons Veny (1958-59: 110-111), el pas de madrina a 'llevadora' degué realitzar-se a partir del significat de 'mujer que asiste a alguien que recibe un sacramento'.

${ }^{65}$ El femení padrina es documenta ja l'any 1280 en el Llibre de cort de justícia de València: «totes les persones de moros qui eren ladoncs en aquel loch reeberen babtisme, e foren feites cristianes per man d'él testimoni, ab padrins e padrines cristians de natura que hi foren demanats» (Diéguez 2002: 41).

${ }^{66}$ Prova de com la llengua veïna podia influir sobre els catalanoparlants de l'època són les sospites que, davant la identitat formal dels mots, tenia Marc Antoni d'Orellana (1731-1813) sobre un hipotètic origen castellà del valencià madrina 'llevadora' (cf. Martí 1994b: 136). Els diccionaris castellans, des del segle XV, registren madrina aplicat a la dona que presenta un infant a les fonts baptismals o assisteix en el sagrament del matrimoni, però no amb el de 'llevadora' ( $c f . N T L L E, N T L E)$. Amb aquest valor trobem notícia de madrina 'llevadora' en Gonzalo de Berceo ( $c f$. Alonso 1986: 1335), i era conegut en aragonés medieval. Així, apareix en dos passatges aragonesos en documentació cancelleresca de 1381, que Colón (1993: 52) dubta entre considerar un calc o una isoglossa compartida amb el català; i, així mateix, madrina es recull en documents notarials saragossans dels segles XIV i XV «para designar tanto a las comadronas judías como a las cristianas» (Blasco 1995: 165).
} 
da matrona com a sinònim de llevadora, a més de mantenir el sentit tradicional de 'mare de família, dona noble'; també en Escrig (1851) matrona 'por madre de familia noble y virtuosa, y por muger experta en embarazos y autorizada para algún reconocimiento'; en EscLl «lo mismo que comare, madrona y llevadora». A la segona meitat del XIX, Eduard Escalante contraposava la popular comare, aficionada i sense estudis especialitzats, a la matrona, amb estudis, i al comadró: «La comare. No parle de la matrona, / o profesora de parts, / que té els seus estudis fets / en el art de partechar. / Parle de la que tan sols / se pot dir afisionà, / y únicament en la pràctica / el títul seu té fundat. / Més com les dones cuant volent / una cosa ponderar, / no se detenen en fer / de una formiga un caball, / així han fet de la Malaena / una comare acabà, / donant-li més fama y nom / que a un comadró acreditat» (en els Tipos d'auca de Llombart, 1878: 207). Per tant, veiem com el vell mot comare patia una restricció semàntica davant l'empenta de matrona, aplicat al sentit més tècnic $\mathrm{i}$ especialitzat de la pràctica ginecològica. En castellà matrona 'la comadre que partea y assiste a las que están de parto’ figura en el Diccionario de autoridades (1734), que el documenta en Calderón, ${ }^{67}$ i continua en la llengua actual, on té també un sentit especialitzat ('comadre, y con especialidad la que se halla legalmente autorizada para asistir a las parturientas'). ${ }^{68}$ En francés $m a$ trone 'sage-femme' fou viu entre els segles XIV i XVII, però al segle XVIII aquest sentit s'envellí en l'ús ordinari (cf. Rey, 2006; Dictionnaires d'autrefois).$^{69}$ Per tant, no seria descartable una interferència castellana en la expansió tardana de matrona 'llevadora' en català, sentit que no és inclòs en el DIEC. Una major extensió sembla haver aconseguit en català el castellanisme comadrona,${ }^{70}$ que actualment es troba repartit al llarg de tot el domini lingüístic, juntament amb les diferents formes tradicionals (ALDC núm. 479 «La llevadora»). ${ }^{71}$

${ }^{67}$ Aquesta accepció, però, no consta en els diccionaris anteriors ( $\left.c f . N T L L E, N T L E\right)$, ni la recull Alonso (1986).

${ }^{68}$ Amb aquest sentit professional és definit el mot en el DRAE des de l'edició de 1914 , però això no significa que no fos així ja a la segona meitat del segle XIX, com ho hem vist en valencià en Escalante, tot i que les edicions del DRAE d'aquest segle continuessen amb la inèrcia de la definició tradicional ('comadre que asiste a las que están de parto').

${ }^{69}$ En occità matrona 'sage-femme' és també antic, i continua en alguns parlars ( $c f$. Raynouard 1844: IV, 122; Lespy, Raymond 1970: II, 59; Mistral 1979: II, 298; FEW, VI / 1, 503-504; Levy 1991).

${ }^{70}$ En castellà el mot comadrón es creà al segle XVIII, derivat de comadre, i segurament primer fou aplicat als homes que feien unes funcions tradicionalment reservades a les dones, a les comadres. En el DRAE de 1780 figura comadrón «el que hace el oficio de comadre de parir. Es voz y oficio nuevamente introducido en España»; en l'edició de 1884 se'n canvia la definició: 'cirujano que asiste a la mujer en el acto del parto', i no s'hi introdueix el femení comadrona fins l'edició de 1925, com a sinònim de comadre 'partera' ( $c f . N T L L E)$. En català, com hem vist amb la cita d'Escalante, i com mostren Escrig (1851), EscLl i MGad, al segle XIX també es coneixia només en masculí, comadró.

${ }^{71}$ En alguns punts on conviu amb comare, llevadora o prenedora els parlants valoren aquestes com a formes tradicionals o arcaiques, i comadrona com a forma moderna. En canvi, l'ALDC no 
Altres mots usats per Bernat que podrien incloure's en aquest apartat són, per exemple: ase, aguaitar 'traure el cap, o una part de la cara, per una obertura, per damunt o per entre qualque cosa, per tal de mirar', ä̈na, acorar 'consumir (un cigar)', ${ }^{72}$ boqueró 'forat (en un teixit)', bromeig 'grumeig', cabecet 'coll de la camisa', calces de traveta ${ }^{73}$ caliu, capseta, cinqueta, ert 'rígid, enravenat', 'tibat, entonat, ufanós', escombrar 'estossegar, fent cert moviment i soroll amb la gargamella per desembarassar-la o per fer senya a algú', esgolar-se, espampolar, esprella (varietat d'alga), ferratja, fregall, fumatell 'fumadell', garguilot, jaç 'lloc on acostuma de jaure un animal', i en sentit figurat 'amagatall' ${ }^{74}$ jònec, llepassa, marmolar, melis, moixeta,${ }^{75}$ moixó (mena de peix petit), molinada, orceta, parança, parot 'teuladí mascle', parpall 'parpella'76 i 'pestanya', ${ }^{77}$ polsera 'pèls que creixen damunt els polsos, entre l'orella i l'ull', ramàs 'granera rústica', ros, samaruc 'capgròs', sortit 'moviment brusc del cos produiit per una sensació sobtada, ensurt', trau 'forat (en un objecte)'78 i 'ferida en el cap', ${ }^{79}$ trespol 'sostre', verdanc, xanglot 'sanglot'.

Alguns mots representen solucions valencianes, sovint compartides amb altres parlars, que no hauríem de deixar caure en l'oblit, davant les formes adoptades preferentment per la llengua literària. Per exemple, amelar 'atraure, enllepolir', banquet 'marxapeu, llindar', barandat 'envà', bascoll 'clatell, nuca', batzoles

recull matrona, que, com hem vist, sí que tenia ús al segle XIX. Per la seua part, Coromines (DECat, $\mathrm{V}, 184$ ) informa que, amb el sentit de 'llevadora', comadrona i matrona «han fet estralls, sobretot en les regions meridionals».

$72 C f$. «-Moscatell!... Al puesto, y apaga pronte eixe sigarro. -Deixe'm acorar la punta (...), que encara no se'n passa l'hora...» (S 114), accepció no enregistrada en el DCVB ni en el DECat, relacionada amb 'abrusar la llenya encesa, fer-la caliu fins al més endins, fins al cor', que el $D C V B$ recull a Mallorca i Castelló, sense documentació; amb els sentits de 'ferir en el cor', 'matar', 'ferir greument, aclaparar' acorar és ja medieval.

${ }^{73}$ En l'expressió tindre més anys que les calces de traveta. En el DCVB calça de traveta 'la que només cobreix des del genoll fins al turmell i es subjecta davall el peu amb una tireta' (val. i tort.), sense documentació; en el DECat (VIII, 734) calces de traveta 'antiga mitja pròpia del vestit típic dels pagesos valencians i tortosins», que documenta en els Tipos de Martí Gadea: «el tal refrà deu ser més antic que les calses de traveta». En l'inventari dels béns del comte d'Oliva, l'any 1550, es documenten ja «unes calces saragüells de stamenya borrella, ab mantingala y traveta, forrades totes de pell» (Felip 2000: 335).

${ }^{74}$ Cf. «Ve un capità retirat. / (...) Però en vano s'ha espossat / a esclafar-se (...) els nasos, / buscantlos la pista als chasos / de Cabrera y compañia» (T 130), extensió del sentit de 'llit', com en fer jaç 'fer estada', recollit a Castelló de la Plana (DECat, IV, 888).

75 Amb el sentit d' 'òliba': «Pos no ha ensomiat que entremich d'una nubolà de gats, ratolins, sapos, moixetes y atres avechuchos de la sarpa llarga, habia caigut en l'infern!» (D 173-174), i en sentit figurat, en la locució fer (una dona) la moixeta morta 'afectar interessadament candidesa', formada sobre moix 'gat', a partir del caràcter enganyós i astut que hom atribueix a aquests fèlids.

76 «la que, tancant els parpalls, / busca (...) / plors y treballs» (A 20).

77 «Torta... y plens de parpalls rulls / els ulls» $(\mathrm{Fe} 8)$, «Les selles estaben (...) tan faltes de ploma (...), y els parpalls de l'ull dret (...) es distingien en tanta pena» (D 117).

78 «caygué un bac (...) / y es féu sis traus... en les calses» ( $D 60)$, jugant amb el doble sentit del mot, que pot aplicar-te també a una ferida en el cap.

79 «-Y això, eixe cap chorrant sanc? -Ha caigut un bac y m'ha fet un trau» (S 164). 
'matraca', braç 'branca gruixuda d'un arbre', dur al be 'dur a collibè', capell 'capoll', carafal 'cadafal', cudol 'còdol', escaldapoll, escama i escarot 'esvalot, escàndol, avalot', esguitar 'esquitxar', esguit 'esquitx', espinàs 'columna vertebral', estómec 'estómac', ${ }^{80}$ estrela 'estrella', estudi 'cambra, habitació de dormir', ${ }^{81}$ fraura 'maduixa', furum 'ferum', gallet 'úvula, gargamelló, galló (gallonet) 'grill, part de certs fruits separada de les altres parts per membranes', gargamell 'gargamella', mançaneta 'botó', redolada 'rodalia', replanell 'replà d'escala', sarcet 'cerceta (au palmípeda)'.

L'estudi del vocabulari de Bernat i Baldoví contribueix, doncs, a aportar noves dades a la història del lèxic català, en un període tradicionalment poc aprofitat. Un dels aspectes sobre el qual podem extraure informacions d'interés és el de la sinonímia, que presenta alguns exemples valuosos per a l'estudi de la variació lèxica en el valencià, i en el català en general, del segle XIX, de vegades amb interessants diferències semàntiques entre els mots relacionats. Als casos que hem anat veient en pàgines anteriors, en podríem afegir d'altres com titot $\mathrm{i}$ polit ${ }^{82}$ xumenera i fumeral, estalviar i aforrar, alfals i herba, ${ }^{83}$ botella i ampolla, bacó, porc i cerdet, abans, ans i antes,${ }^{84}$ company i companyero, ${ }^{85}$ toro i bou, lluquet i palleta, escolà, escolanet i acolitet, ${ }^{86}$ afonar i afondar, ${ }^{87} \mathrm{o}$ aparell i aparato $^{88}$, entre altres.

\footnotetext{
${ }^{80}$ Recordem que estómec és la forma habitual en la llengua medieval, i actualment en català occidental, d'acord amb l'evolució fonètica regular de la -A- interior posttònica. Cf. Coromines (DECat, III, 784), el qual pensava que «hauria estat més just» adoptar estómec «com a grafia normal».

${ }^{81}$ En el $D C V B$ aquest sentit d'estudi és considerat valencià i balear, documentat en el períodic mallorquí La Roqueta. El nom, que trobem ja al segle XVI, segurament procediria del fet que en les cases de les classes acomodades, o en les d'homes de lletres, en la cambra privada, on es dormia, estava també l'escriptori. En l'inventari de béns del senyor d'Alaquàs llegim: «en lo studi de migant scala fonch atrobat lo següent: Primo, hun lit de posts ab sos petges. Item, en lo altre studi aprés següent fonch atrobat lo següent: Primo, un lit de camp usat ab dos matalafs e una fillola, ab sa vànova e flaçada; item, un scriptori de noguer vell vuyt; item, una caixa de noguer ab molt papers de poca importància» (a. 1543) (Juan 1984: 271); d'ací passaria a designar, per extensió, en les cases dels llauradors, la cambra de dormir, encara que no es destinés expressament a una funció intel·lectual, com ho veiem en els col-loquis valencians dels segles XVIII i XIX, i en Bernat i Baldoví (cf. Martí 2011).

${ }^{82}$ Titot és la forma que utilitza habitualment Bernat i Baldoví per designar el 'gall dindi', mot valencià i tortosí $(D C V B)$, que documentem des del segle XVIII; també fa servir el sinònim polit, i el mot titotico, que sembla un diminutiu acastellanat de titot; així com tit, que hi designa una varietat d'ocell menut ( $c f$. Martí 2011).

${ }^{83}$ Bernat utilitza habitualment herba (herba tendra i herba seca, ja assecada) per referència a l'aliment del bestiar, especialment l'alfals, i amb el mot alfals sembla designar més aviat el camp sembrat d'alfals, com ho trobem ja en documents valencians del segle XVII (Martí 2011: 364); reducció d'herba d'alfals (herba alfals), perquè segurament aquesta és tradicionalment l'herba més utilitzada com a aliment del bestiar. En la carta de poblament de Carlet (1520) hom destria l'alfals de les altres herbes usades com a farratge: «Ittem, és acostumat que tot moro té franca micha fanecada de alfals franch e de qualsevol altra herba, per obs de ses bèsties, y si.n tindrà més de alfals de la micha fanecada, y si tindrà més herba de la micha fanecada, ha-la partir ab lo senyor al quart» (Benítez 1986: 204). Vegeu també l'ALDC (m. 813 «L'herba per al bestiar»).

${ }^{84}$ Predominen abans i ans sobre el castellanisme antes, documentat des d'Onofre Pou.
} 
Bernat i Baldoví escriu bou referit a l'animal mascle castrat, usat per a llaurar: «no són de bous per a llaurar» ( $T 24)$, però també com a sinònim de toro: «en la present correguda / es maten bous sinse achuda» (T 204), i corregudes de bous: «per tot el present mes de chuliol ha de haber corregudes... de bous reals» ( $T$ $156)$; juntament amb toro: «funsions de toros» ( $T$ 198), «feren tres dies de toros / allà en la Pobla del Duc» (D 29), i correguda de toros: «està disposta una famosas correguda de toros» (T 40). Igualment, al segle XVIII, Carles Ros emprava toro i bou com a sinònims, referits a l'animal brau, no castrat. Segons Coromines (DECat, II, 183), el mot bou «almenys en el Nord del domini, es limita estrictament a l'animal mascle però capat, i a partir dels tres anys (...), però a les regions del Migdia sobretot també és normal que s'apliqui al toro (...), i llavors, amb caràcter lax, s'usa col-loquialment com a substitut total de toro, especialment en terres valencianes i mallorquines». Amb tot, veiem que en valencià en temps de Bernat es feia servir encara toro. ${ }^{89}$ Quant a l'ús de bou, aplicat a l'animal brau, que intervé en jocs o festes, es documenta ja a finals del segle XIV en valencià, en una carta dels jurats de la ciutat, amb motiu dels actes festius pel naixement del primogènit del rei: «E axí mateix a aquells del centenar de cavall,

85 Més usat companyero que company per part de Bernat.

${ }^{86}$ En Bernat i Baldoví, com actualment en diferents localitats valencianes, l'escolà és el 'sagristà', mentre que l'acolitet o escolanet és el 'xiquet que serveix missa i ajuda a altres ministeris de l'altar' (veg. Martí 2011).

87 Bernat i Baldoví usa afonar amb els sentits de 'fer anar a fons', transitiu, i 'caure (una cosa) desfent-se sobre els seus fonaments', pronominal; mentre que afondar és intransitiu i es fa servir amb el sentit d' 'aprofundir, estudiar o meditar a fons' (veg. Martí 2011).

${ }^{88}$ El Primer, aparell, s'aplica als estris de pescar i de caçar, mentre que el castellanisme aparato té el sentit de 'solemnitat, ostentació', el qual es documenta en valencià ja a mitjan segle XVI (veg. Martí 2011).

$89 \mathrm{Cf}$. en altres textos valencians al segle XIX: «el serdo pareix un toro, / y les olives, simbombes» (Palanca, Secanistes de Bixquert, 1867, 53), «Al toro més terrible, / com yo puga en mich la plasa / mirar-lo cuatre minuts / fit a fit...» (Escalante, I, 582); formant locucions, prova de la seua popularitat: fet un toro 'molt furiós': «No em diga res, so Colau, / per Déu, qu·estic fet un toro» (Palanca, Llàgrimes de una femella, València, 1859, 9), «Calle, si estic fet un toro; / corre en mi sanc española, / y els insuls de eixa chentola / m'an inflamat contra el moro» (Tordera, Un fill digne de Alacant, Alacant, 1860, 6); bramar com un toro i bramar com el toro en plaça: «No·m parle més d'eixe asumte, / perquè em posaré a bramar / com un toro» (Proclama en forma de coloqui, València, 1808, 4), «Un tir vingué de repent / y li pegà enmitj del bras. / Bramant com el toro en plaça, / s'alsa el ferit a l'instant» (El Fénix, 19, 1844-45, 114), de dolor; calent com un toro: «y calent com un toro, me se ficà en lo cap el anar a les màixqueres del treato aquella nit» (El Mole, 1840-41: I, 347), ponderant els sentiments intensos; fer més mal que un toro: «Vach un mes roder per fora, / y faré més mal q.un toro; / entre una nit a deshora, / mate a huit y... cap a el moro» (Martínez Vercher, En la velà d'un albat, València, 1865, 8); estar més fort que un toro: «Yo, que avans / roncaba com un obús, / y estaba més fort qu·un toro / y era el meu pap un llaüt, / ara me toque y no·m trobe, / pués m'ha quedat com un chunc» (Escalante, II, 135); fer el toro marraix 'comportar-se de forma maliciosa, malintencionada': «El Jorlit, com home vaij / y d'ofici vergonyós, / encés en foch llutjuriós, / y fent el toro marraix, / alçà la vista atrevida» (El Fénix, 12, 1844-45, 71), cap a Tereseta, que venia a suplicar-li pel seu estimat Vaoro; en més malícia que un toro: "Yo, en més malícia que un toro, / me vaig anar acostant / a escoltar lo que parlaven, / per veure si em fea al cas» (Rahonament entre el Rull de Payporta y Albudeca, València, s. a. [1802], 1); anar més empiulat 
dels quals los uns jugassen a les canyes e los altres bornasen per la ciutat de dia (...). E que a pus o altres actes a present no sia procehit, com fer juntes o altres jochs de bous induesquen gran ajustament de gents» (a. 1399) (CICA: 2006 Epistolari Id, c. 147, 1. 80), ${ }^{90} \mathrm{i}$ al segle XV es parla de festa de córrer bous: «Al senyor rey és plaent que digmenge primervinent li sia feta festa de córrer bous» (a. 1417) (CICA: 2006 - Epistolari IIa, c. 33, 1. 4), i festes de bous: «així són estats en plaers e alegries, ab festes de bous e de canyes, de diumenge fins dimecres» (a. 1493) (CICA: 2006 - Cartes Borja II, c. 15, 1. 103). També a Lleida, als segles XV i XVI, es corrien bous en les festes (veg. Farreny, 2004: 459-460), la qual cosa demostra l'existència d'un ús històric més extens de bou amb el sentit de toro, no limitat a les «terres valencianes i mallorquines». També en Pou (1580: 29) córrer de bous. Boalia, ium vel orum, bupetiae, arum, bupetii, orum; i en Torra (1653) jochs de bous o córrer de toros, que no apareix en Font (1637).

Bernat i Baldoví usa habitualment palleta: «carreguí també (...) / palletes» (Te $15)$, «per a ensendre més el foc / ha aplicat unes palletes» $(P 18)$, per referència al 'lluquet'; mot documentat ja en el Tirant (DAg, VI, 24; $D C V B)$, i que recollia Pou (1575: 221), com a sinònim de lluquet: palleta o lluquet. Sulphurata, ae, juntament amb palleta de paper. Sulphuratae ex papyro, i les construccions una manada de palletes i pendre foc ab la palleta de la esca. El mot continuava essent corrent en valencià en el temps de Bernat; l'usaven els sainetistes del segle XIX: «bé te'n recordaràs / de cuant duyes el cabàs / ple de vidres y palletes» (Liern, La mona de Pascua, València, 1862, 29), «en les galtes / poden ensendre'm palleta» (Escalante, I, 408), «montí un comers més tart / de palletes, sabó, espart, / esquers y pedres de foc» (Llombart, Cester, L'agüela Puala, València, 1886, 198), i apareix en els diccionaris valencians de l'època, començant per Sanelo: palleta 'pajuela', palletes 'pajuelas', palletes de sofre 'pajuelas de azufre', palleta o lluquet 'pajuela. Sulphuratum', tret de Pou (Gulsoy 1964: 175, 272); en Lamarca (1839) palleta de lladre 'luquete, alguáquida', forma que el $D C V B$ considera pròpia del valencià; ${ }^{91}$ en Escrig (1851) palleta 'pajica, lla, ta, juela', la palleta d'encendre, siga de canyamiça o de les dites de lladre 'pajuela o luquete, sulfonete' i la palleta de fumar; en EscLl palleta «pedazo delgado de cañaheja, cuerda, etc., mojado en azufre, usado en las casas para encender prontamente luz. Suele tambien llamarse palleta de lladre; lo mismo que lluquet, meja ensofrà, da, cotó ensofrat

que un toro: «Com són les llauradoretes / tan ayroses, aniran / més empiulades que un toro, / en llistes, flocs, farfalans, / agulles, pintes de plata, / pendientes, creus y collars» (Coloqui graciós que tingueren Vadoro el Cert, de Paterna, Sento el Roig y Badoc el Guapo, de Benimàmet, València, s. a. [1802], 4), és a dir, dur molts ornaments; fer-se més gros que un toro real: «En huit dies vas a fer-te / més gros qu·un toro real» (Roig i Civera, Un chuche munisipal, València, 1900, 13). ${ }^{90}$ En el $D C V B$ no es documenta fins al segle XVI en els Consells a un casat d'Andreu Martí Pineda.

${ }^{91}$ En el DCVB palleta 'Bocí de palla, de paper, de fusta, etc., amb un cap ensofrat, que serveix per a encendre foc' i palleta de lladre 'lluquet o misto que s'encén sense soroll'. 
y esca de cardet». En canvi, al Principat sembla que era un arcaisme al segle XIX, com mostren Belv., Labèrnia (1839-40) i el Quintilingüe, on palleta figura com a veu antiquada, per lluquet. ${ }^{92}$

Bernat i Baldoví fa servir també lluquet, però només en la locució fet un lluquet i en la comparació encés com un lluquet o més encés que un lluquet, usades per a ponderar l'enuig, i de fet, en els textos populars valencians dels segles XVIII i XIX normalment documentem lluquet en aquestes locucions i comparacions, o en altres de semblants, com anar més a pressa que un lluquet (veg. Martí 2011), o ser (algú) un lluquet 'ser una persona molt temperamental': «-Y tu callabes? / -Yo? Qué!... / Si le gastaba más guasas...! / Em refilà las tenasas / una vez que la miré! / -Eixa dona era un lluquet» (Ariño, Un héroe de Cochinchina, València. 1863, 18). ${ }^{93}$ El mot lluquet es troba en el Curial e Güelfa i en Jaume Roig $(D C V B)$, i, segons Coromines (DECat, V, 308), l'usaria ja Jaume Marc (1372); figura també lucat 'lluquet' en un llibre de cort reial mallorquí del segle XIV ( $c f$. Miralles 1984: 47-48, 121). Apareix en la lexicografia catalana des del segle XVI (cf. DECat), i continua en els diccionaris del segle XIX ( $c f$. Martí 2011), en Belv. lluquet 'lo que servex per encéndrer fog', en Labèrnia (1839-40): lluquet 'tros de caramuixa, etc. ensofrat per a encéndrer llum, i lluquet de bribó 'cordill tot ensofrat que també serveix per a encéndrer llum', ${ }^{94}$ que recorda força la $p a$ lleta de lladre valenciana. Però tant lluquet com palleta, aquest darrer probablement més corrent, en sentit propi, en el valencià del segle XIX, patiren en aquella centúria la competència del misto, que acabà desplaçant-los. ${ }^{95} \mathrm{El}$ nou referent, que fou des del principi anomenat amb un terme també nou, es troba, segons Coromines (DECat, V, 625), usat en català, primer en plural, mistos, ${ }^{96}$ des de principis del segle XIX, «per designar la tigeta combustible amb mixtura inflamable», diferent del lluquet o palleta, «que era un bocinet de branquilló ensofrat que s'encenia en contacte amb un cos en ignició» (Veny 2009a: II, 111). Bernat i Baldoví no esmenta encara el misto, ${ }^{97}$ però el trobem en altres escriptors

\footnotetext{
${ }_{92}$ No es troba palleta amb el sentit de 'lluquet' en els diccionaris anteriors de Font (1637), Torra (1653) ni Lacavalleria (1696).

${ }^{93}$ L'ús figurat de lluquet el trobem ja a finals del segle XV. Segons Coromines (DECat, V, 308), «entre els escriptors de la fi del nostre període clàssic és gairebé un lloc comú d'usar-lo figuradament per a cosa que incendia, o excita o s'encén i abranda, sovint sensualment».

${ }^{94}$ Un poc abans figurava en el diccionari manuscrit de fra Albert Vidal, datat l'any 1818: lluquet de brivó o sofrí (Colón, Soberanas 1986: 151).

${ }^{95}$ Francesc Puig i Pascual en Los valencianos pintados por si mismos (1859, pp. 228-229) ja donava compte de la decadència de les palletes, i de l'ofici de palleter, des de l'aparició dels fósforos: «La invención de los fósforos casi ha venido a suprimir su representación (...) [de les palletes]. Y hoy, por miserable que sea una familia, siempre tiene provista la cocina de su correspondiente caja de fósforos», mentre que «las consabidas pajuelas (...) apenas se conocen hoy en la cocina de las casas».

${ }^{96}$ Per a Coromines, el singular misto s'hauria format a partir del plural mistos, més usat.

${ }^{97}$ Fa servir cerilleta, però no amb el sentit modern de 'misto', que es troba en alguns punts catalans ( $A L D C$, núm. 286 «Els llumins»), sinó, segons sembla, per referència al ble d'una llàntia d'oli (veg. Martí 2011).
} 
valencians de vocació popular una mica posteriors, com Francesc Palanca o Constantí Llombart, i, abans, es documenta en els Successos de Barcelona (a. 1835) (veg. Martí 2011). ${ }^{98}$ Segons el DCVB, misto és pres del castellà mixto id. També Veny (1984: 194-195) considera misto 'llumí' un castellanisme, que penetraria en català amb l'explotació comercial del nou referent. En canvi, Coromines (DECat, $\mathrm{V}, 625)$ creu que mistos no és castellanisme, pensant segurament en un català mist, variant de mixt (< MIXTUS), amb un plural mistos, d'on s'hauria extret el singular misto. ${ }^{99}$

\section{BIBLIOGRAFIA.}

$A=$ Comedieta nova, en un acte y en vers, titulada L'agüelo Pollastre (paròdia del Tenorio), Sueca, edición del semanario «El Sueco», imp. de Sueca de Máximo Juan, s. a. ( $1^{\mathrm{a}}$ ed. València, emprenta de la Rechenerasió Tipogràfica, 1859).

Alberola, E. (1928) Refraner valencià, València, Arte y Letras.

Albiol Vidal, S. (2003) Establiments de Vinaròs, Vinaròs, Centre d'Estudis del Maestrat.

$A L D C=$ Veny, J. + Pons, L. Atles Lingüístic del Domini Català, Barcelona, IEC, 5 vols., 2001-10 (en curs de publicació).

Alibert, L. (2002) Dictionnaire occitan-français selon les parlers languedocines, Toulouse, Institut d'Etudes Occitanes.

Alonso, M. (1986) Diccionario medieval español, Salamanca, Universidad Pontificia.

$B=$ Cuadro de costums de la Ribera Baixa del Chúquer, titulat Batiste Moscatell o La mona de Pascua, València, imprenta de Chusep Maria Ayoldi, 1862.

Bakhtin, M. (1999 [1941]) La cultura popular en la Edad Media y en el Renacimiento. El contexto de François Rabelais, Madrid, Alianza.

Barnils, P. (1916) Vocabulari català-alemany de l'any 1502, Barcelona, IEC.

Battaglia, S. (1970-1999) Grande dizionario della lingua italiana, Torino, Unione Tip. Editrice Torinese.

Beltran i Cavaller, J. S. (2010) Vocabulari de crüllla, Benicarló, Onada edicions.

Benavent, R. (ed.) (1987) Privilegi reial de la vila de Quatretonda del 1587, Quatretonda, Ajuntament de Quatretonda.

\footnotetext{
98 Actualment, misto és el mot general en català; lluquet, segons l'ALDC (núm. 286 «Els llumins»), resta en alguns punts mallorquins, menorquins i del català central, i palletes fou recollit a Alfafar («amb sofre a un extrem») i a Torís, però com un referent antic. Alberola $(1928: 99,111)$ recollia les locucions estar u que s'encén en una palleta i encendre's com un lluquet, i Pérez i Navarro (2000: 208) arreplega lluquet a Crevillent en la locució poc freqüent encés com un lluquet 'molt enutjat'.

${ }^{99}$ En el DRAE no figura mixto com a sinònim de fósforo fins l'ed. de 1899, encara que segurament era conegut abans. $C f$. per relació a composts químics incendiaris: «A los quince dias de llegado, fueron otros portugueses con mixtos incendiarios que se los dieron ocultamente al fugitivo fingido» (a. 1837) (Martín Fernández de Navarrete: Viajes al Maluco de Fray García de Loaísa y Álvaro de Saavedra, ap. CORDE).
} 
Benítez Sánchez-Blanco, R. (1986) «Las cartas pueblas del condado de Carlet y los conflictos sobre su aplicación», Saitabi, 36, pp. 187-212.

Blasco, R. (1984) La insolent sàtira antiga, Xàtiva, Ajuntament de Xàtiva.

Blasco Martínez, A. (1995) «Médicos y pacientes de las tres religiones (Zaragoza siglo XIV y comienzos del XV)», Aragón en la Edad Media, 12, pp. 153-182.

Broch, J. (1771) Promtuario trilingüe, Barcelona, Pablo Campins.

Cabrera, J. M. (1868) Vocabulario valenciano-castellano, València, F. Campos.

Cahner, M. (2002) Literatura de la revolució i la contrarevolució (1789-1849), II, Barcelona, Curial.

Carbonell Bòria, M. J. (2003) «1596: Las Ordinaciones de la Jana (Castellón)», en El món urbà a la Corona d'Aragó dels 1137 als decrets de Nova Planta: XVII Congrès d'Història de la Corona d'Aragó, Barcelona, PUB, vol. 3, pp. 133-138.

Cavanilles, A. (1795) Observaciones sobre la historia natural, geografía, agricultura, población y frutos del Reyno de Valencia, Madrid, imprenta real.

CICA = Corpus Informatitzat del Català Antic, J. Torruella (dir.), M. Pérez Saldanya, J. Martines i V. Martines, 2006. http://webs2002.uab.es/sfi/cica/.

Colomina, J. (1991) El valencià de la Marina Baixa, València, Generalitat Valenciana.

Colón, G. (1993) El lèxic català dins la Romània, València, Universitat de València.

Colón, G. (1997) Estudis de filologia catalana i romànica, València / Barcelona, IIFV / PAM.

Colón, G. (1999) «Sobre la llengua de Josep Bernat i Baldoví», en M. Nicolàs (ed.): Bernat i Baldoví i el seu temps, València, PUV, pp. 327-330.

Colón, G. (2011a) «Revisió crítica de les Regles», en Colón, G. + Ferrando, A. Les Regles d'esquivar vocables a revisió, València / Barcelona, IIFV / PAM.

Colón, G. (2011b) Lexicografia, lèxic i crítica textual, Castelló / Barcelona, Fundació Germà Colón Domènech / Publicacions de l'Abadia de Montserrat.

Corbera Pou, J. (2000) Caracterització del lèxic alguerès, Palma de Mallorca, Universitat de les Illes Balears.

CORDE = REAL ACADEMIA ESPAÑOLA: Banco de datos (CORDE) [en línea]. Corpus diacrónico del español. http://www.rae.es [març de 2012].

$D=$ La Donsayna, imprenta de Sánchiz (13 números, de l'1 de setembre de 1844 al 23 de febrer de 1845).

DAg = Diccionari Aguiló (1915-1934). Materials lexicogràfics aplegats per M. Aguiló i Fuster. Revisats i publicats sota la cura de P. Fabra i M. de Montoliu, Barcelona, IEC, 8 toms.

DCVB = Alcover, A. M. + Moll, F. de B. (1988) Diccionari Català-Valencià-Balear, Palma de Mallorca, Moll, 10 vols.

DCECH = Coromines, J. con la colaboración de José A. Pascual (2000-2002) Diccionario crítico etimológico castellano e hispánico, Madrid, Gredos, 6 vols.

DECat = Coromines, J. (1980-2002) Diccionari etimològic i complementari de la llengua catalana, Barcelona, Curial, 10 vols. 
Dictionnaire de la Provence et du Comté-Venaisin, Marsella, Jean Mossy, 1785.

Dictionnaires d'autrefois. French dictionaries of the 17th, 18th, 19th and 20th centuries. The ARTFL Project, Department of Romance Languages and Literatures, University of Chicago. http://artfl-project.uchicago.edu/

Diéguez, M. À (2002) Clams i crims en la València medieval segons el Llibre de cort de justícia (1279-1321), Alacant, Universitat d'Alacant.

Doñate Sebastià, J. M. (1979) «Vocabulari d'arcaismes de l'arxiu de Vila-real (Castelló)», Anuario de Filología, 5, pp. 403-482.

Du Cange, Ch. (1883-87) Glosarium mediae et infimae latinitatis, Niort, Fabre. http://ducange.enc.sorbonne.fr/

$E=$ Meló-y-drama tot en una pesa titulat Un ensayo fet en regla o Qui no té la vespra no té la festa, València, llibreria de Àngel Aguilar, 1909.

Escalante, E. (1894) Colección completa de las obras dramáticas de Don Eduardo Escalante, València, Federico Domènech, 3 vols. [citem pel número del volum].

Escartí, V. J. (1992) El Llibre del mustassaf d'Albalat de la Ribera, Albalat de la Ribera, Ajuntament.

Escartí, V. J. (1998) Memòria privada, València, 3 i 4.

Escartí, V. J. (ed.) (1999) Joaquim Aierdi, Dietari, Barcelona, Barcino.

Escrig, J. (1851) Diccionario valenciano-castellano, València, Ferrer de Orga.

EscLl = Escrig, J. + Llombart, C (1887) Diccionario valenciano-castellano, València, Pascual Aguilar.

Espinal, M. T. (2006) Diccionari de sinònims de frases fetes, Barcelona, Universitat Autònoma de Barcelona.

Esteve, J. + Belvitges, J. + Juglà, A. (1803-1805) Diccionario catalán-castellano-latino, Barcelona, Tecla Pla, 2 vols.

$F=$ Un fandanguet en Paiporta. Cuadro dominical de costums de l'Horta de Valènsia, edición del semanario «El Sueco», Sueca, imp. de Máximo Juan, 1913 (1ª ed. València, imprenta de D. Chulià Mariana, 1857).

Fausto, V. (2006) Lèxic vila-realenc en perill d'extinció, València, Brosquil.

Felip Sempere, V. (2000) Recull per a una història de Nules, Nules, Caixa Rural de Sant Josep de Nules.

Ferrando, A. (1983) Els certàmens poètics valencians del segle XIV al XIX, València, IAM.

Ferrando, A. (ed.) (1995) Pere Jacint Morlà, Poesies i col-loquis, València, IVEI.

FEW = Wartburg, Walther von (1956-) Französisches etymologisches Wörterbuch, Zbinden, Basel.

Figuera, P. A. (1840) Diccionari mallorquí-castellà, Palma, Esteva Trias.

Font, A. (1637) Fons verborum et phrasium, Barcelona. 
Furió, A. (ed.) (1999) Gaspar Guerau de Montmajor, Breu descripció dels mestres que anaren a besar les mans a sa majestat del rei don Felip al Real de la ciutat de València a 8 de febrer any 1586, València, Universitat de València.

Furió Vayà, J. (2001) «Els poemes valencians de Josep Vicent Ortí. Estudi i edició», Caplletra, núm. 31, pp. 115-150.

Fuster, J. (2002) Les Constitucions del convent de Sant Josep de València (segle XVI), València, Universitat de València.

Galán Castañ, J. + Galán Pérez, M. (1997) Lèxic esmortoüt de la parla de Fraga, Osca, IEBC / IEA.

Garcia, H. (1927) «Más sobre el «creix y el exovar»», Boletín de la Sociedad Castellonense de Cultura, 8, pp. 250-253.

Garcia i Osuna, A. (2003) Setze coses evengudes en lo lloch de Moncada (1632-1687), València, Ajuntament de Moncada.

Gil Vicent, V. (2002) Ordenances municipals de Vila-real (segles XIV-XVIII), València, Universitat de València.

Guinot, E. + A. J. Mira (2008) «Fiscalidad urbana y distribución y consumo de la producción agrícola en Valencia (siglos XIV-XV)», en Los tributos de la tierra: fiscalidad y agricultura en España (siglos XII-XX), València, Universitat de València, pp. 137-162.

Gulsoy, J. (1964) El Diccionario Valenciano-Castellano de Manuel Joaquín Sanelo, Castelló de la Plana, Sociedad Castellonense de Cultura.

Hernandis, P. J. (2007) Notícia de la vila d'Albalat de la Ribera de Xúquer, Albalat de la Ribera, Ajuntament.

Hospitaler, J. (1869) Vocabulario castellano-menorquín y viceversa, Maó, imp. de Miguel Parpal.

Iborra Lerma, J. M. (1981) Realengo y señorío en el Camp de Morvedre, València, $\mathrm{Pu}-$ blicaciones de la Caja de Ahorros y Socorros de Sagunto.

Imbs, P. (dir.) (1971-1994) Trésor de la langue française, París, Gallimard.

Juan Redal, E. (1984) «Dades per a l'estudi de la societat valenciana del segle XVI: Els últims codicils testamentaris i l'inventari de béns d'En Jaume Garcia d'Aguilar, senyor d'Alaquàs», en Crónica de la XIV Asamblea de Cronistas Oficiales del Reino de Valencia, València, Academia de Cultura Valenciana, pp. 231-272.

Julià, E. (1921) «Almoneda e inventarios valencianos», Boletín de la Sociedad Castellonense de Cultura, 2, pp. 332-337.

Labèrnia, P. (1839-40) Diccionari de la llengua catalana ab la correspondència castellana y llatina, Barcelona, Hereus de la Viuda Pla, 2 vols.

Lacavalleria, J. (1696) Gazophylazium catalano-latinum, Barcelona, Antoni Lacavalleria.

Lairón, A. J. (2001) Libre de diverses statuts e ordinacions fets per lo consell de la vila de Algezira, València, Universitat de València.

Lamarca, Ll. (1839) Ensayo de un diccionario valenciano-castellano, València, J. Ferrer de Orga. 
Lespy, V. + Raymond, P. (1970) Dictionnaire béarnais ancien et moderne, Genève, Slatkine Reprints.

Levy, E. (1991) Petit dictionnaire provençal-français, Raphèle-lès-Arles, Culture Provençale et Méridionale Marcel Petit.

López Terrada, M. L. (1986) El Hospital General de Valencia en el siglo XVI (15121600), València, Universitat de València, tesi doctoral, 3 vols.

Machado, J. P. (1987) Dicionário etimológico da língua portuguesa, Lisboa, Livros Horizonte, 5 vols.

Mandingorra Llavata, M. L. (2007) Llibre de Miquel Ferrer, palmiter (1612-1634), Castelló, Sociedad Castellonese de Cultura.

Maranges i Prat, I. (1991) La indumentària civil catalana. Segles XIII-XV, Barcelona, IEC.

Marí Garcia, E. (2010) El llibre de família dels Roig de València. La transmissió de la memòria a través d'un llibre de compte i raó, València, Universitat de València, tesi de màster, dirigida per Carmen Pérez Aparicio i Amparo Felipo Orts.

Martí Mestre, J. (1991) «El Coloqui nou entre el tio Pelut, Sardineta y Polseres, un testimoni escrit dels avalots del 1801 al País Valencià», en Estudis de Llengua i Literatura Catalanes. XXII. Miscel-lània Jordi Carbonell 1, Barcelona, PAM, pp. 133176.

Martí Mestre, J. (1994a) El «Libre de Antiquitats» de la Seu de València. Estudi i edició, València / Barcelona, IUFV / PAM, 2 vols.

Martí Mestre, J. (1994b) «Una contribució a la lexicografia del segle XVIII: Marc Antoni d'Orellana», en Estudis de Llengua i Literatura Catalanes, 28. Miscel-lània Gernà Colón 1, Barcelona, PAM, pp. 111-145.

Martí Mestre, J. (1997) Literatura de canya i cordell al País Valencià, València, Denes.

Martí Mestre, J. (2001) «Llengua i societat en la medicina tradicional i popular dels segles XVIII i XIX», en Estudis de Llengua i Literatura Catalanes XLIII. Miscel-lània Giuseppe Tavani 2, Barcelona, PAM, pp. 97-142.

Martí Mestre, J. (2008) Els col-loquis valencians atribuïts a Carles Leon, València, Denes.

Martí Mestre, J. (2009) Joaquim Bernat i Baldoví. La tradició popular i burlesca, Barcelona, Afers.

Martí Mestre, J. (2011) Diccionari de Josep Bernat i Baldoví (1809-1864) en el seu context històric, València, Denes.

Martí Mestre, J. (e. p.) «El català de mitjan segle XVII a través del testament i de l'inventari dels béns del sotssagristà Pere Joan Tomàs», en premsa.

Martí Mestre, J. + Serra Estellés, X. (2009) La Consueta de la Seu de València dels segles XVI-XVII. Estudi i edició del ms. 405 de l'ACV, València, Facultad de Teología San Vicente Ferrer, 2 vols.

Martines, J. (1998) El Diccionario valenciano de Josep Pla i Costa (1817-1890), Alacant, Institut de Cultura Juan Gil-Albert.

Martines, J. (2000) El valencià del segle XIX. Estudi lingüístic del Diccionario valenciano de Josep Pla i Costa, Alacant / Barcelona, IIFV / PAM. 
Martínez Rondán, J. (1984) Rebedor del notari Pere Guarch, Morvedre 1648, 1649 i 1650, Sagunt, Publicacions de la Caixa d'Estalvis i Socors de Sagunt.

Mas, A. + Monjo, J-Ll. (2001) «La mallorquinització onomàstica a la València del segle XVII. L'aportació de la vila de Santa Margalida», en Congrés Internacional de Toponímia i Onomàstica Catalanes, València, Denes, pp. 119-144.

Meseguer, Ll. (2009) Antologia d'escriptors castellonencs, València, Acadèmia Valenciana de la Llengua.

MGad = Martí Gadea, J. (1891) Diccionario valenciano-castellano, València: José Canales Romà.

Mi = Bernat i Baldoví, J. (1997) Miscel·lània. Obra completa 8, ed. facsímil, ed. coordinada per J. Antoni Carrasquer, València, Afers.

Miquel i Planas, R. (ed.) (1911) Cançoner satírich valencià dels segles XV y XVI, Barcelona, Biblioteca Catalana.

Miralles i Monserrat, J. (1984) Un llibre de cort reial mallorquí del segle XIV (1357-60), Palma de Mallorca, IEB.

Mistral, F. (1979) Lou Trésor dou Félibrige, Raphèle-lès-Arles, M. Petit.

Morell i Montadi, C. (1986) La famosa comèdia de la gala està en son punt, Barcelona, Curial.

Nagore, F. (1994) «Los occitanismos en aragonés», Alazet, 6, pp. 119-173.

Novo Aurélio = Buarque de Holanda Ferreira, A. (1999) O Dicionário da Língua Portuguesa. Século XXI, Rio de Janeiro, Nova Fronteira.

NTLE = Nieto Jiménez, L. + Alvar Ezquerra, M. (2007) Nuevo Tesoro Lexicográfico del Español (s. XIV-1726), Madrid, Arco Libros.

NTLLE = Real Academia Española (2000) Nuevo Tesoro Lexicográfico de la Lengua Española, Madrid, Espasa, edición en DVD.

Orellana, M. A. d' (1923-24) Valencia antigua y moderna, València, Acción Bibliográfica Valenciana, 3 vols.

$P=$ Meló-y-drama tot en una pesa, titulat Pascualo y Visanteta o El Tribunal de Favara, València, imp. de La Opinió, 1861.

Palay, S. (1974) Dictionnaire du Béarnais et du Gascon, París, ECNRS.

Paredes, M. (ed.) (2001) Antoni Febrer i Cardona, Diccionari menorquí, espanyol, francès i llatí, Barcelona, IEC.

Pellas, Sauveur-André (1723) Dictionnaire provençal et français, Avignon, Offray.

Pellicer, J. E. (1986) La "Rondalla de rondalles" de Lluís Galiana. Estudi lingüístic $i$ edició, València, IFV.

Pérez i Navarro, V. J. (2000) «El procés de substitució lèxica en el parlar valencià popular: especialització semàntica i fòssils lingüístics a la població de Crevillent», en Estudis de Llengua i Literatura. XL. Homenatge a Arthur Terry 4, Barcelona, PAM, pp. 197-222.

Pla Alberola, P. J. (1986) Cartas pueblas del condado de Cocentaina, Alacant, Instituto de Estudios Juan Gil-Albert. 
Pons, A. (1949) Libre del mostassaf de Mallorca, Mallorca, CSIC.

Pou, O. (1575 [1580]) Thesaurus puerilis, València, Pere de Huete (2 ${ }^{\mathrm{a}}$ ed. Barcelona, Joan Pau Menescal, 1580).

Puig Escoí, A. (2002) Diccionari de la indumentària, Castelló, Diputació de Castelló.

$Q=$ Entretenimiento bilingüe, en cuatro cuadros y en verso, titulado Qui tinga cucs que pele fulla, u Obedecer al que manda, València, Establecimiento tipográfico de El Valenciano, 1855.

Quintilingüe = Diccionari català-castellà-llatí-francés-italià. Per una societat de Catalans, Barcelona, Joseph Torner, 1839, 2 vols.

Raynouard, F. J. (1844) Lexique roman ou Dictionnaire de la langue des troubadours, Paris, Chez Silvestre.

Rey, A. (dir.) (2006) Dictionnaire historique de la langue française, París, Le Robert.

Roca i Cerdà, A. (1806) Diccionario manual de la lengua catalana y castellana, Barcelona, Compañia de Jordi Roca y Gaspar.

Rohlfs, G. (1977) Le Gascon. Etudes de philologie pyrénéenne, Tübingen, Max Niemeyer.

Ros, C. (1739) Breve diccionario valenciano-castellano, València, Josep Garcia.

Ros, C. (1764) Diccionario valenciano-castellano, València, Benito Monfort.

Ros, C. (1771) Corrección de vozes y phrases que el vulgo u común de Valencia usa, o ha introducido hablando (u queriendo hablar) en su materno idioma, Valencia, Francisco Burguete.

Rosanes, M. (1864) Miscelánea que comprende un vocabulario valenciano-castellano, València, José María Ayoldi.

Sanchis Guarner, M. (1972) La ciutat de València, València, Cercle de Belles Arts.

Simbor, V. (1980) Els orígens de la Renaixença valenciana, València, IFV.

$S=$ El Sueco. Periòdic de corfa y molla, València, imprenta de López, setembre-novembre 1847 (13 números).

Sanxis i Forriols, J. Ll. (2002) Fraseologia popular inspirada en el món agrícola i religiós, València, Brosquil.

Segura Llopes, J. C. (1996) Estudi lingüístic del parlar d'Alacant, Alacant, Institut de Cultura «Juan Gil-Albert».

Simón, J. (1946) «Los hornos y flecas», Boletín de la Sociedad Castellonese de Cultura, 22, pp. 259-262.

Sòria, J. (1960) Dietari, València, Acción Bibliográfica Valenciana.

$T=$ El Tabalet, València, imprenta de Blat (13 números, del 2 de maig de 1847 al 31 de juliol de 1847).

Tarifa dels preus de les teles y altres sorts de robes y mercaderies que entren en lo present Principat de Cathalunya y comptat de Cerdanya, Barcelona, Rafel Figueró (anys 1683, 1692, 1698, 1704). 
Tarifa dels preus y pesos de les mercaduries per a la millor exacció y cobransa de la cissa de pas que es col-lecta en les taules de la contribució de la present ciutat y llochs situats de aquella, València, Francisco Ciprés, 1671.

Tarifa eo aranzell dels preus y estimacions a com dehuen passar y estimar-se totes les robes y mercaderies que entraran en lo present regne en los anys 1628 y 1629, València, per Juan Batiste Marçal, 1628.

Te $=$ Cuadro de costums valensianes en mànegues de camisa, titulat La tertúlia de Colau, o Pataques y caragols, València, Juan Mariana y Sanz, editor, 1867 ( $1^{\mathrm{a}}$ ed. València, imprenta de D. J. Mariana, 1850)

Torra, A. (1653) Dictionarium seu thesaurus catalano-latinus verborum ac phrasium, Barcelona, Antoni Lacavalleria.

TP 1858 = Falla de Sen Chusep, en la plaseta del Teatro Prinsipal de Valènsia, en l'añ 1858, València, imprenta de D. Julián Mariana, s. a.

Unos amigos (1859) Diccionario manual o Vocabulario completo mallorquín-castellano, Palma, imp. de la Viuda de Villalonga.

$V=$ Comèdia nova en un acte, titulada El virgo de Visanteta, o El parlar bé no costa un pacho, s. 1., 1845.

Varela Merino, E. (2009) Los galicismos en el español de los siglos XVI y XVII, Madrid, CSIC, 2 vols.

Veny, J. (1958-59 / 1960) «Paralelismos léxicos en los dialectos catalanes», Revista de Filología Española, 42, pp. 91-149; 43, pp. 117-202.

Veny, J. (1984) Estudis de geolingüística catalana, Barcelona, ed. 62.

Veny, J. (2009a) Petit atles lingüístic del domini català, Barcelona, IEC, 2 vols.

Veny, J. (2009b) Per una història diatòpica de la llengua catalana, Barcelona, PAM.

Veny, J. + Massip, À. (2011) Scripta menorquina, Barcelona / Maó, IEC / IME.

Verge Caballer, J. A. (2008) El parlar d'Alcalà de Xivert, Castelló, Associació d'Amics de Mainhardt.

Zaforteza y Musoles, Diego (1948) «Historia de la fundación del Lugar Nuevo de Fenollet y de su señorío», Saitabi, 6, pp. 5-47. 
